\title{
Methodology for Determining Time-Dependent Mechanical Properties of Tuff Subjected to Near-Field Repository Conditions
}

\author{
J. D. Blacic \\ R. Andersen
}
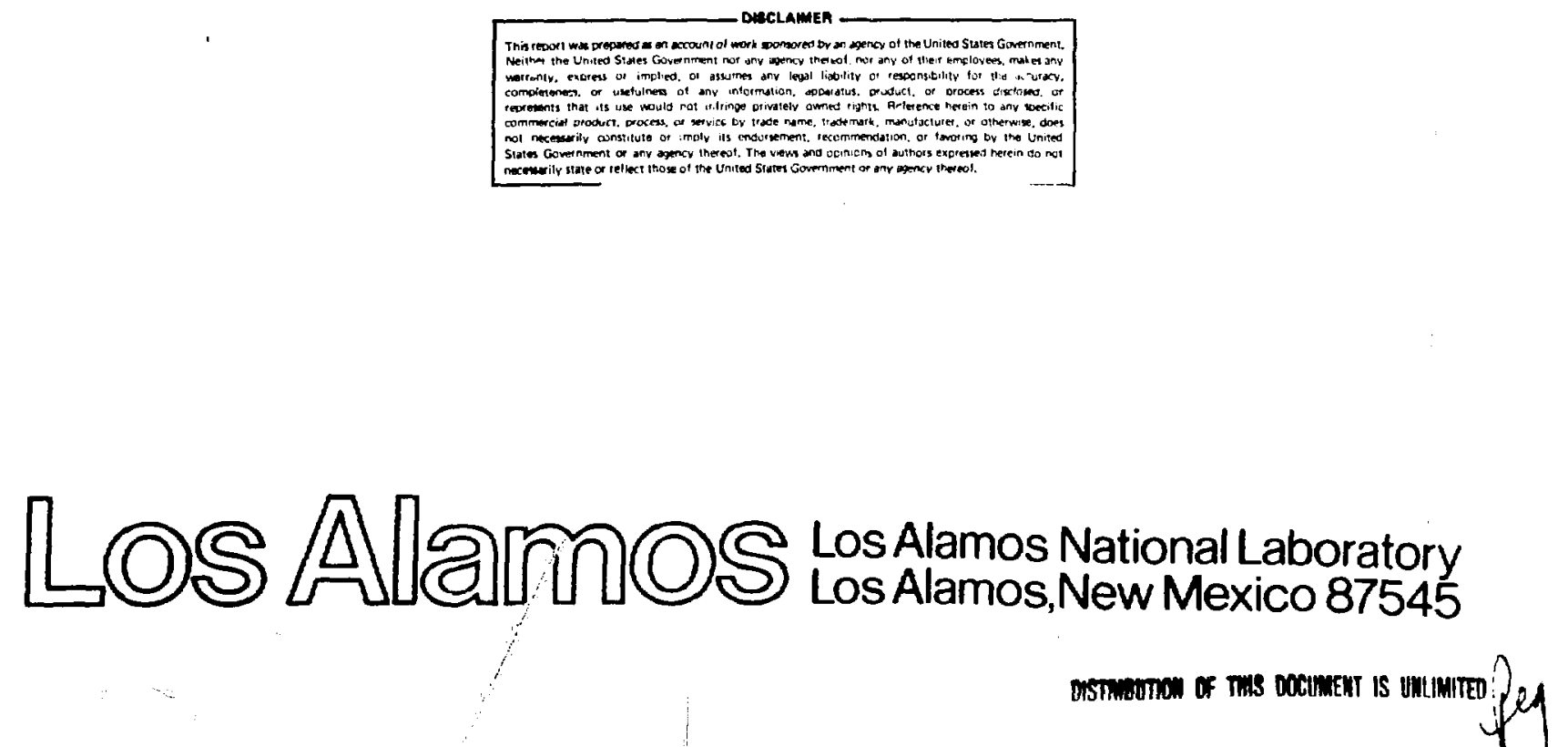
METHOR 3LOGY FOR DETERMINING TIME-DEPENDENT MEC.HANICAL PROPERTIES OF TUFF SUBJECTED TO NEAR-FIELD REPOSITURY CONDITIUNS

by

J. D. Blacic and R. Andersen

\begin{abstract}
We have established a methodology to determine the time dependence of strength and transport properties of tuff under conditions appropriate to a nuclear waste repository. Exploratory tests to determine the approximate magnitudes of thermomechanical property changes are nearly complete. In this report we describe the capabilities of an apparatus designed to precisely measure the time-dependent deformation and permeability of tuff at simulated repository conditions. Preliminary tests with this new apparatus indicate that microclastic creep failure of tuff occurs over a narrow strain range with little precursory Tertiary creep behavior. In one test, deformation under conditions of slowly decreasing effective pressure resulted in failure, whereas some strain indicators showed a decreasing rate of strain.
\end{abstract}

I. INTRUDUCTION

The purpose of this preliminary report is to introduce the topic of time-dependent mechanical properties of tuff and to describe an approach for measuring these properties.

The objectives are listed below.

(1) Measure deformation of tuff over an extended time at conditions of stress, temperature, confining pressure, and water pore pressure likely to be encountered in a nuclear waste repository. From these exploratory tests, we will determine if the magnitude of strength and mineralogic changes warrants a more extensive set of measurements proposed in (2) and (3) below. 
(2) Measure deformation of tuff over a sufficient range of physical variable: to enable the formulation of a constitutive description that can be used in numerical models for design and performance evaluation of a repository. Particular emphasis will be placed on evaluating the possibility of delayed failure in tuff and what controls it.

(3) A subsidiary goal is to measure the time variation of water permeability in tuff and how it is affected by slow deformation of the rock matrix.

A detailed background discussion of time-dependent microclastic deformation of repository-candidate rocks is given by $\mathrm{Blacic}^{l}$ and will only be summarized here. The basic problem is that present design and performance calculations for a repository assume that thermomechanical and transport properties for a particular rock are constant over time. These properties are determined by standard, short-time engineering tests that do not examine a possible time dependence. Repository designs are unusual in that they must stand the test of very long term performance. Analysis that does not take into account time effects can lead to erroneous answers. For example, thermal conductivity might decrease over time as a result of slow, progressive microcracking of rock in the near field. Thermal calculations that do not incorporate this effect will underestimate near-field temperatures. Similarly, permeability of tuff is relatively low because of the apparently low connectivity of porosity. This could change substantially over time during slow deformation. Nuclide transport models that do not include this change would overestimate transit times.

A reliable evaluation of the magnitudes of these time phenomena is difficult, principally because of a lack of data. We describe below a two-part experimental approach to obtaining the required data. First we will make a preliminary evaluation of the existence of the time-dependent phenomena in tuff and a rough estimate of their magnitudes. Then, if, based on these results, analysis indicates that more precise measurements are required for design and performance calculations, we will proceed with these measurements.

The first part of our approach is almost complete. An exploratory test was performed in which samples of a variety of tuff types from the southwest part of the Nevada Test Site (NTS) were exposed to a range of temperatures, confining pressures, and water pore pressures for times of 2 to 6 months. A set of thermomechanical properties was measured at ambient conditions before and after this exposure and compared. Preliminary results indicate that 
substantial and statistically significant changes occurred in tensile strength, compressive strength, and mineralogic content in some tuff types. Comparisons of data from before and after exposure of thermal conductivity and permeability are currently in progress. Details of this test are given in Ref. 2. Guided by these results, we are in the process of extending the measurements with long-term deformation (creep) tests that should indicate the magnitude of strength change more precisely. A prototype apparatus was designed and constructed for the creep measurements, and a few check-out tests have been performed. Details of the apparatus and the first few tests are given below.

\section{DEVELOPMENT OF EXPERIMENTAL EQUIPMENT}

Because laboratory data on time dependence of mechanical and transport properties of rock will have to be extrapolated orders of magnitude in time even to encompass the operational time period, rather precise measurements of these properties are required. Physical variables such as temperature and pressure must be controlled, and response measurements must be made over time periods of months. This requires specialized testing equipment not widely available. Consequently, we designed and built a prototype apparatus that incorporates what we believe to be current state-of-the-art capabilities in rock mechanics testing equipment. Considerable effort and time was spent developing the apparatus in order to reduce programmatic risk. If more detailed creep measurements will be required, as now appears to be the case based on the preliminary testing described above, then availability of suitable equipment will reduce time delays in the program. Even so, tests of such long duration over a range of physical conditions and rock characteristics would prevent us from obtaining this information on an accelerated or crash basis.

The apparatus is best described in terms of distinct subsystems. These are (1) differential stress, (2) confining pressure, (3) pore pressure and permeability, and (4) computer control and digital data acquisition systems. A. Differential Stress Subsystem

The purpose of the differential stress subsystem is to rapidly attain the desired axial differential stress on the test sample and to precisely maintain that value for the duration of the test. The differential stress is applied only after steady values of confining pressure, pore pressure, and temperature 
have been achieved. Because of the long duration of the planned tests, it is desirable to have an automated control systen so that an operator need not always be present. The computer control and digital data acquisition subsystem is described below. We will describe only the mechanical portion of the subsystem here.

Figure 1 shows the basic components of the subsystem. The jacketed sample is contained in an externaliy heated pressure vessel and pressurized with silicone oil. Details of the pressure vessel design are discussed below with the description of the confining pressure subsystem. The pressure vessel is mounted within, and axiai force is applied by a standard four-post hydraulic load frame. Detalls of the load frame are not significant; the one we use in the prototype system is capable of generating $500000 \mathrm{lb}$ of force. The important aspects of the system are how the hydraulic ram pressure is generated and automatically adjusted to maintain a constant differential stress on the test sample (shown in Fig. 2).

The ram is manually advanced or retracted for initial contact or unloading of the sample, respectively, by means of an air/oil pump (P1) actuated through regulator R1 by low-pressure house air. The direction of ram movement is determined by electric solenoid valves SV5 and SV6, and pressures are monitored on gauges G3 and G4. At the beginning of a test, once contact of the sample and the loading piston is made, the manual system is no longer used. High pressure is then applied suddenly to the ram by opening solenoid valve SV1. Before opening SV1, an accumulator (AC) is precharged from a high-pressure gas bottle (B1) through regulator R2 and gauge G2. The accumulator is a bladder type that separates the charging gas from the hydraulic oil. Because there is essentially no friction in this type of accumulator, a differential stress within about $5 \%$ of the desired value can be obtained by accurately precharging. This value is rapidly attained at sample strain rates of about $10^{-3} \mathrm{~s}^{-1}$. About 2 seconds after $\mathrm{SV} 1$ is opened, automatic triming of the accumulator gas pressure begins with feedback from an internal force transducer. The internal force gauge consists of a strain gauge with four active arms that is bridge-mounted on a steel end piece between the sample and the loading piston. Differential stress on the sample is calculated from the force gauge signal and the current cross sectional area of the sample that is determined from strain gauges on the sample and the 


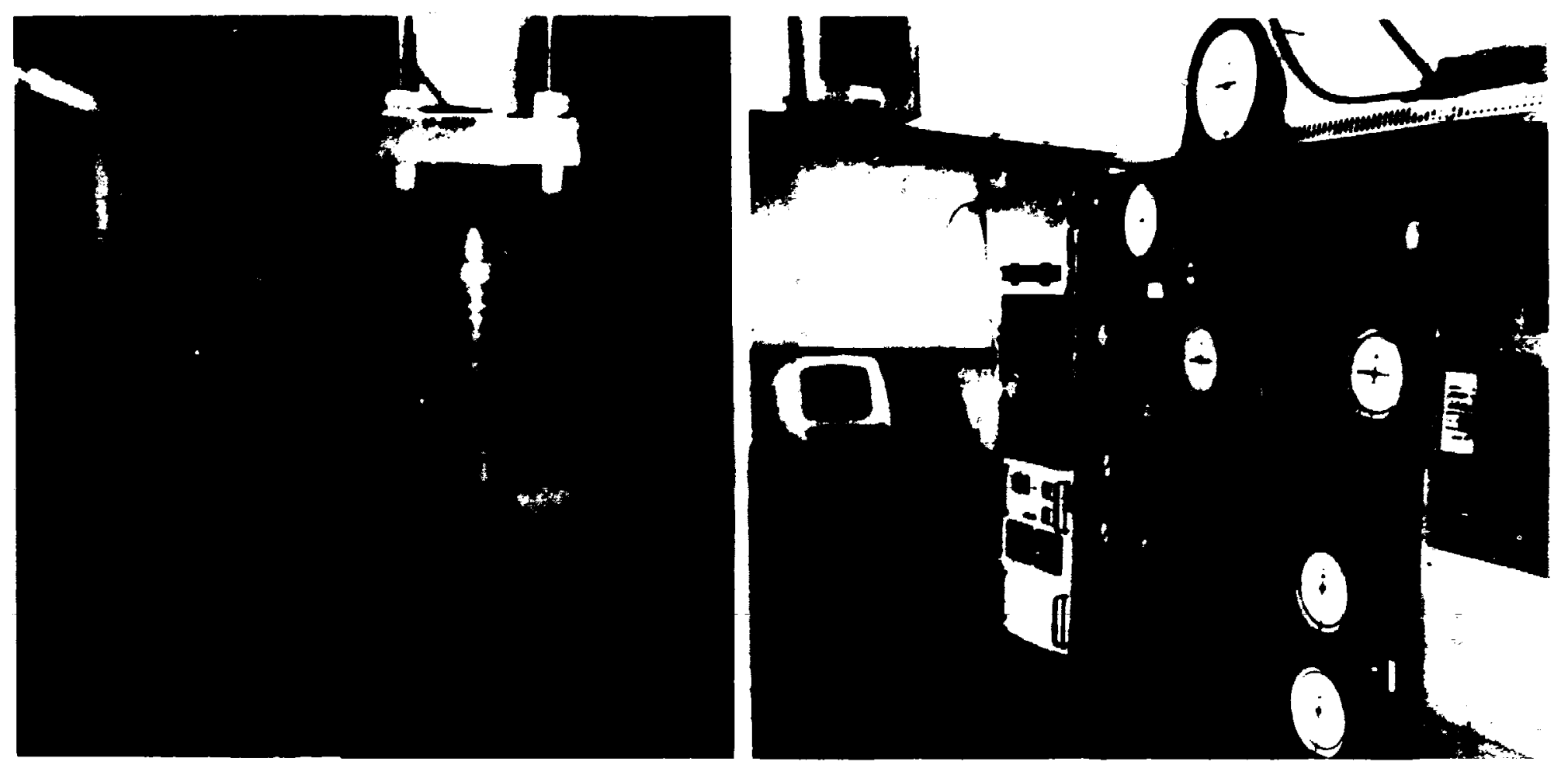

Fig. 1.

Photograph of the apparatus. 


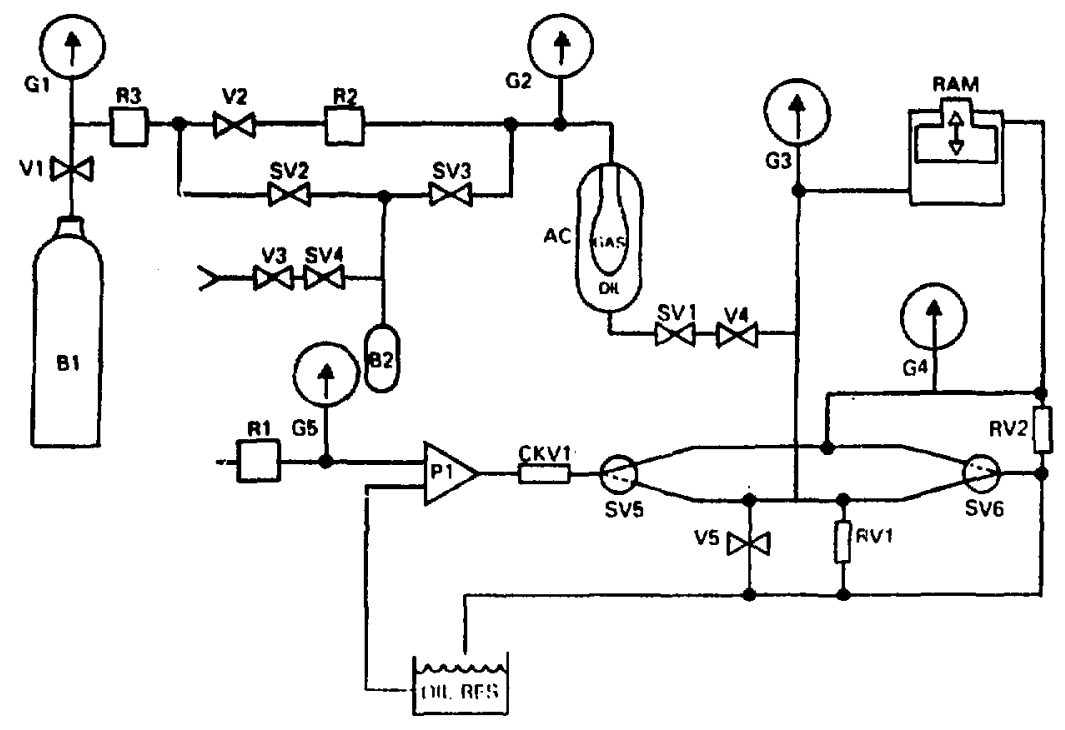

Fig. 2.

The differential stress subsystem. The following symbols are used: $V=$ manual valve, $S V=$ electric solenold valve, $R=$ regulator, $B=$ bottle, $A C=$ accumulator, $R V=$ relief valve, $P=$ pump, $C K V=$ check valve, and $G=$ gauge.

starting sample dimensions. The current stress is compared to the desired value and any difference controls the action of the control loop.

The actuator part of the control loop consists of solenoid valves SV2, SV3, SV4; regulator R3; manual throttling valve $V_{3}$; and bottle $B 2$. Valves SV2, SV3, and SV4 are nomally closed. If, for example, an increment of pressure is required to increase the stress towards the desired value, SV2 is momentarily opened and then closed, trapping a small volume of gas in B2 at a pressure (determined by R3) higher than that in the accumulator. This increment of pressure is then injected by opening and closing SV3. To lower the applied stress, the reverse process takes place, venting an increment from the accumulator through SV4 and V3. This triming process is under complete computer control, the details of which are described in Sec. II.D. Typically, the system is capable of maintaining a differential stress on the sample with about $0.25 \%$ precision.

\section{B. Confining Pressure Subsystem}

A schewatic of the confining pressure subsystem is shown in Fig. 3 . Various pressure vessels may be used in this subsystem. The one we most commonly use accepts an NX. size sample $15.4 \mathrm{~cm}$ in diameter) and is capable of 70 


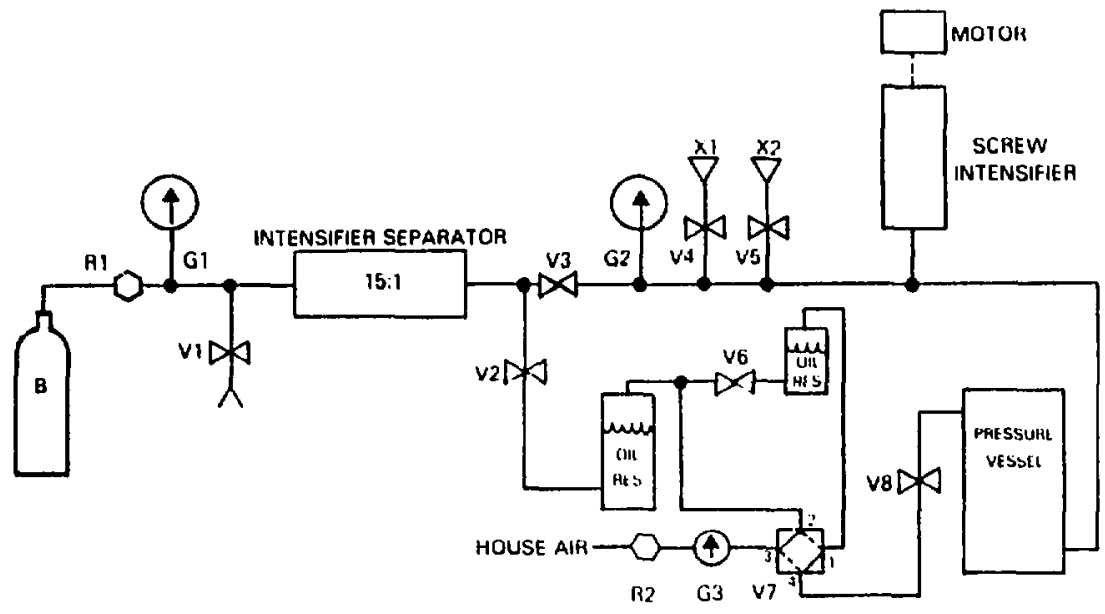

Fig. 3.

Schematic of the confining pressure subsystem. The following symbols are used: $B=$ bottle, $V=$ manual valve, $R=$ regulator, $G=$ gauge, and $X=$ pressure transducer.

$\mathrm{MPa}$ (10 000 psi) pressure and $250^{\circ} \mathrm{C}$ using external band heaters. Electrical feed-throughs for up to 40 signals are provided for internal instrumentation of the sample. These normally consist of three pairs of axial and circumferential strain gauges mounted at $120^{\circ}$ intervals around the sample, three axial LVDT displacement transducers mounted on steel buttons that are epoxied to the sample and rotated $60^{\circ}$ from the strain gauges, three or four thermocouples at different heights along the sample, and the internal force transducer. The rock sample is isolated from the confining pressure medium (DOW 710 silicone oil) by an RTV silastic or other barrier painted on the sample or by a viton rubber jacket. In the latter case, strain gauges or LVDT buttons cannot be mounted directly on the sample surface. Sample pore pressure access is through the sample pedestal and a hollow upper end cap.

Primary confining pressure is generated by a 15:1 piston intensifier actuated by compressed gas through regulator $R 1$. Once pressure is attained, this system is valved off, and fine control is obtained by means of an automated, screw-driven intensifier. Pressure is measured by one of several strain gauge pressure cells, depending on pressure range and Bourdon tube gauges. The motor-driven screw intensifier is computer controlled using a feedback signal from one of the pressure transducers. By adjusting motor speed and transducer sensitivity, pressure can be controlled to within a few 
pounds per square inch over long time periods. At large sample strains, screw piston displacement can be measured to obtain sample volume strain using the method described by Wawersik. ${ }^{3}$

C. Pore Pressure and Permeability Subsystem

A schematic of the pore pressure subsystem is shown in Fig. 4. Initial water pore pressure is obtained by means of an air/water pump after first evacuating the sample and pressure lines. Once pressure is attained, the pump is valved off, and fine control is obtained by actuating a bladder-type accumulator with compressed gas. This system is sufficient for long-term control of pore pressure within about $2 \%$. For finer control required for permeability determinations, one or the other of two subsystems is used. At permeabilities above about 1 mdarcy, the sample is isolated with a Constametric-brand liquid chromatograph pump. This pump is capable of generating constant flow rates of 0.1 to $10 \mathrm{ml} / \mathrm{min}$ at line pressures up to 40 MPa. At a given flow rate, the pressure drop across the sample is measured by a differential pressure transducer (X2) to an accuracy of $0.25 \%$. The permeability is then calculated from Darcy's equation for viscous flow through a porous medium as

$$
k=\mu \nu L / \Delta P,
$$

where $k$ is permeability, $\mu$ is the viscosity of water, $v$ is the volume flow rate per unit time per unit cross sectional area, and $\Delta P$ is the pressure drop over à sample of length $L$.

At very low permeabilities, flow rates are too low for any reasonable pressure drop and so a relaxation method is used. The method is that described by Brace et al. ${ }^{4}$ in which a pressure step is applied to the sample, and the exponential decay of pressure is recorded from the differential pressure gauge. Permeability is then related to the pressure decay constant, $\alpha$, by the equation

$$
k=\frac{\alpha \beta \mu L V_{2} V_{1}}{A\left(V_{2}+V_{1}\right)},
$$

where $k$ is permeability, $\alpha$ is the decay constant, $\beta$ is the isothermal compressibility of water, $\mu$ is the dynamic viscosity of water, $L$ is the sample length, $A$ is the sample cross sectional area, and $V_{1}$ and $V_{2}$ are the volumes of pore fluid reservoirs at the two ends of the sample. The pressure step can be applied in a number of ways. For automated measurements in which the mean 


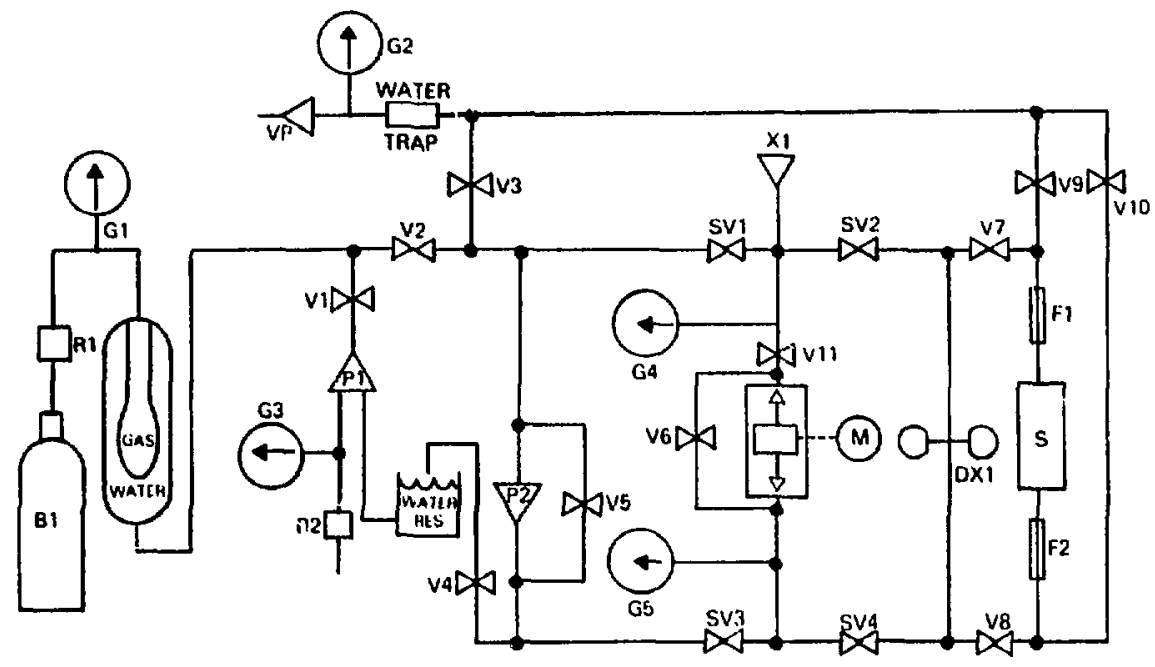

Fig. 4 .

The pore pressure and permeability system. The following symbols are used: $B$ $=$ bottle, $R=$ regulator, $V=$ manual valve, $S V=$ electric solenoid valve, $V P=$ vacuum pump, $P=$ pump, $G=$ gauge, $S=$ test sample, $F=$ filter, $M=$ motor, $X=$ pressure transducer, and $D X=$ differential pressure transducer.

pore pressure is constant, a motorized, double-acting piston pump may be used. The pressure difference is produced by advancing the piston in one direction or the other and then opening solenoid valves SV2 and SV4 to suddeniy apply the pressure step to the sample. A simpler method of applying a pressure step is to suddenly turn the stem of valve $\mathrm{V} 5$.

D. Computer Control and Digital Data Acquisition Subsystem

A block diagram of the computer control and digital data acquisition system is shown in Fig. 5. The principal component of this system is a Digital Equipment Corporation LSI-11 microcomputer and flexible disk system. The computer performs the following functions.

(1) Control Differential Stress. The computer gathers force, confining. pressure, and circumferential strain values from the internal load cell, pressure transducer, and sample-mounted strain gauges, respectively. This information is used to calculate the current value of the true differential stress on the test sample. The computer will then actuate a valve sequence to adjust the force so as to maintain the differential stress at the desired level, as described above. 


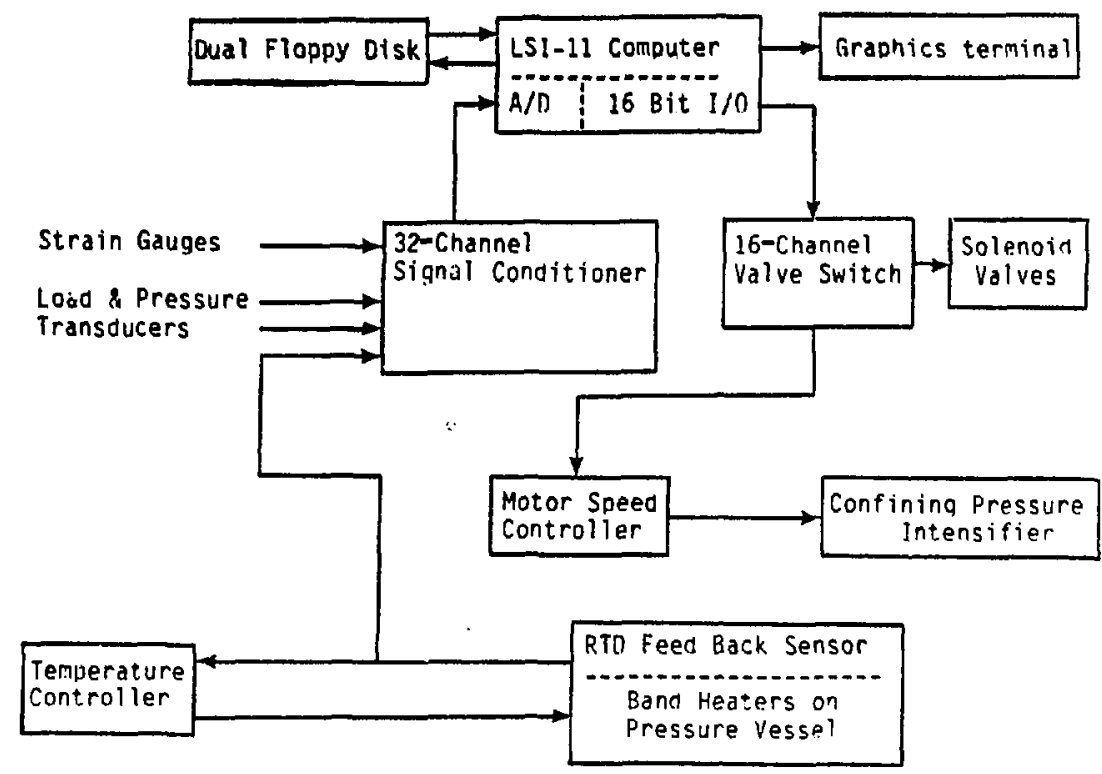

Fig. 5 .

Diagram of computer control and digital data acquisition system.

(2) Control Confining Pressure. Feedback from the confining pressure transducer is used in a process to actuate a motor-driven pressure intensifier and maintain a desired level of pressure. Priority of confining pressure control is lower than that of differential stress. In practice, interaction between the two systems is minimal enough to avoid instability in the overall control process.

(3) Acquire Data. The computer is continually acquiring raw data from the various transducers and storing this information on a floppy disk for postprocessing. There is a real-time display of selected test variables on a computer graphics terminal to help monitor the status of the test. The rate at which data is collected and the number of data channels used is set by the operator.

A 32-channel signal conditioner module can provide excitation, balance, and amplification for transducers, strain gauges, etc. The module, which incorporates the ability to shunt-calibrate strain gauges, has a digital voltmeter to aid setting gain and offset balancing.

A 16-channel valve-switch module and a 16-bit input/output card located in the LSI-11 computer provide the capability of opening or closing any of the 
solenoid valves in the control system. The switch module also contains the power supply necessary to operate the solenoids.

The unit that controls the motor speed also controls the direction and speed of the confining pressure intensifier. The unit can be operated locally or automatically by the computer. Two channels of the valve-switch module are used by the computer to control the direction and time that the intensifier is actuated.

An analog temperature controller is used to control band heaters mounted on the pressure vessel. Feedback is obtained from platinum RTD temperature sensors, and their values are acquired by the computer for postprocessing.

Software for the system is stored on a separate floppy disk. A flow diagram of the control and data acquisition program is shown in Fig. 6, and a Fortran listing is provided in the Appendix.

E. Results of Preliminary Experiments

A few room-temperature, uniaxial creep tests were performed primarily to check out the operation of the differential stress system and the computer conciol and data acquisition programs. We selected samples of Grouse Canyon welded tuff from G-tunnel that were reputed to be from the same block tested by 01 sson and Jones ${ }^{5}$ of Sandia National Laboratories (SNL). According to the SNL data, this tuff should have a uniaxial compressive strength of $180 \mathrm{MPa}$. Consequently, the first test was planned for a differential stress of $100 \mathrm{MPa}$ and ambient confining pressure and temperature. Under these conditions, creep deformation lasting at least 6 weeks was anticipated. However, the sample failed catastrophically as soon as the stress was applied.

Before a second test on this tuff, some uniaxial, constant-displacementrate tests were performed to verify the expected failure strength. At a strain rate of about $10^{-4} \mathrm{~s}^{-1}$, samples with diameters of 1.25 and $2.5 \mathrm{~cm}$ failed at stresses ranging from 65 to $180 \mathrm{MPa}$ (Fig. 7). The weakest sample contained a fragment of pumice that apparently also acted as a weak zone in the 5.4-cm-diam creep test sample. Consequently, the sample selected for the second creep test did not contain any pumice fragments visible at the surface.

In the second test, a differential stress of $75 \mathrm{MPa}$ was applied and held for 5 days (Fig. 8). The load control system worked well. Some minor problems in the data acquisition systems were identified and subsequently corrected. As can be seen in Fig. 8 , there was a very $10 \mathrm{w}$ rate of creep in the axial direction. In the last few days of the test, the average strain rate 

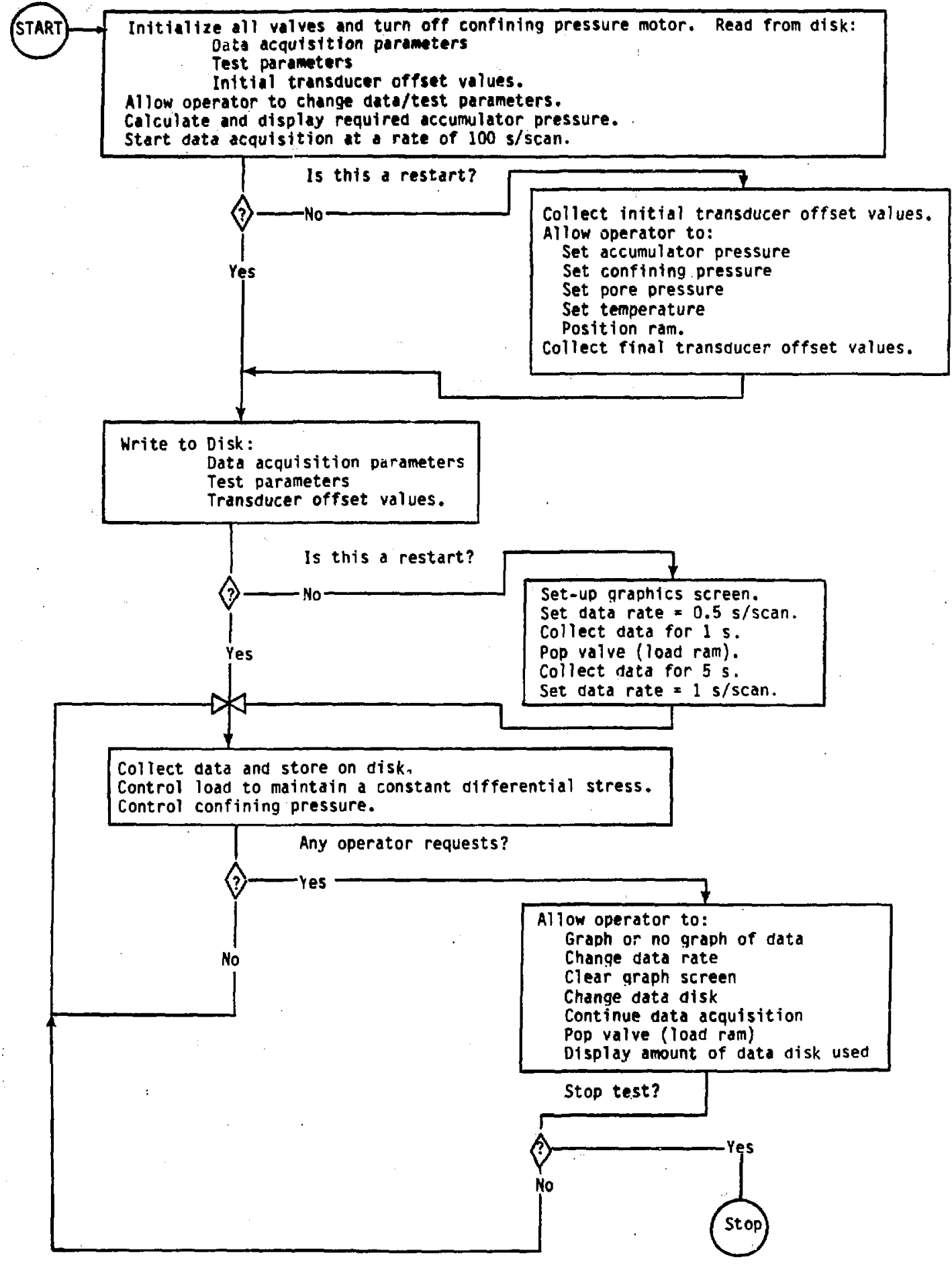

Fig. 6 .

Flow diagram of test control and data acquisition program. 


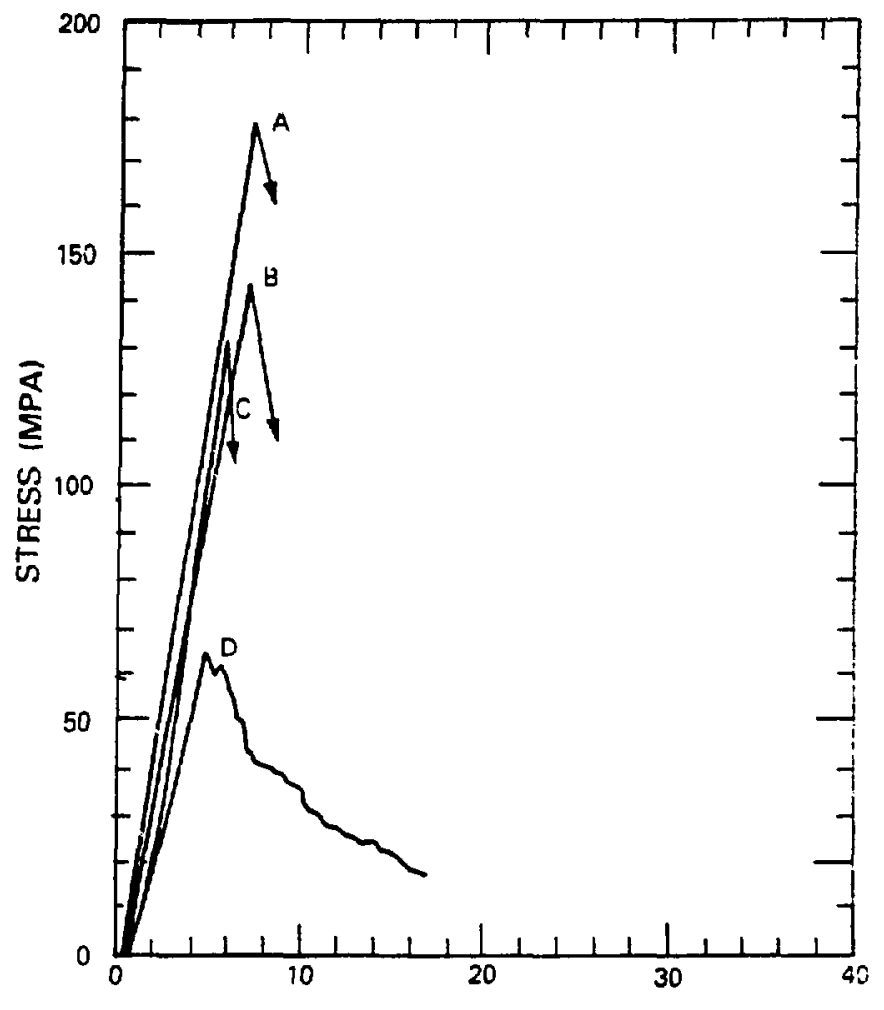

Fig. 7.

Unaxial stress-strain curves for Grouse Canyon welded tuff at $25^{\circ} \mathrm{C}$. $A$ and $B$ are 0.5-in.-diam cylindrical samples and $C$ and $D$ are 1-in.-diam samples.

was $\sim 7 \times 10^{-10} \mathrm{~s}^{-1}$. Most of the axial strain was recovered immediately upon unloading; the remaining amount was recovered within a few days. This observation leads us to believe that the creep strain was due to slow closing of pre-existing cracks preferentially oriented perpendicular to the principal stress direction (also, no new cracks were produced). Therefore, because we believed the sample was not damaged, we decided to reload it at a higher stress level. The sample was loaded to $100 \mathrm{MPa}$, which again should have been well below the short-time failure strength if no weak zones were present.

However, this sample again failed immediately as the higher stress was applied. Figure 9 shows the first few seconds of the test. Comparison of Fig. 8 and 9 illustrates the wide dynamic range of our digital data acquisition system and the short risetime of the stress application. The comparison also shows that at $75 \mathrm{MPa}$, the strains are the same as in the earlier loading to $75 \mathrm{MPa}$, and only a small increase in strain from this level 


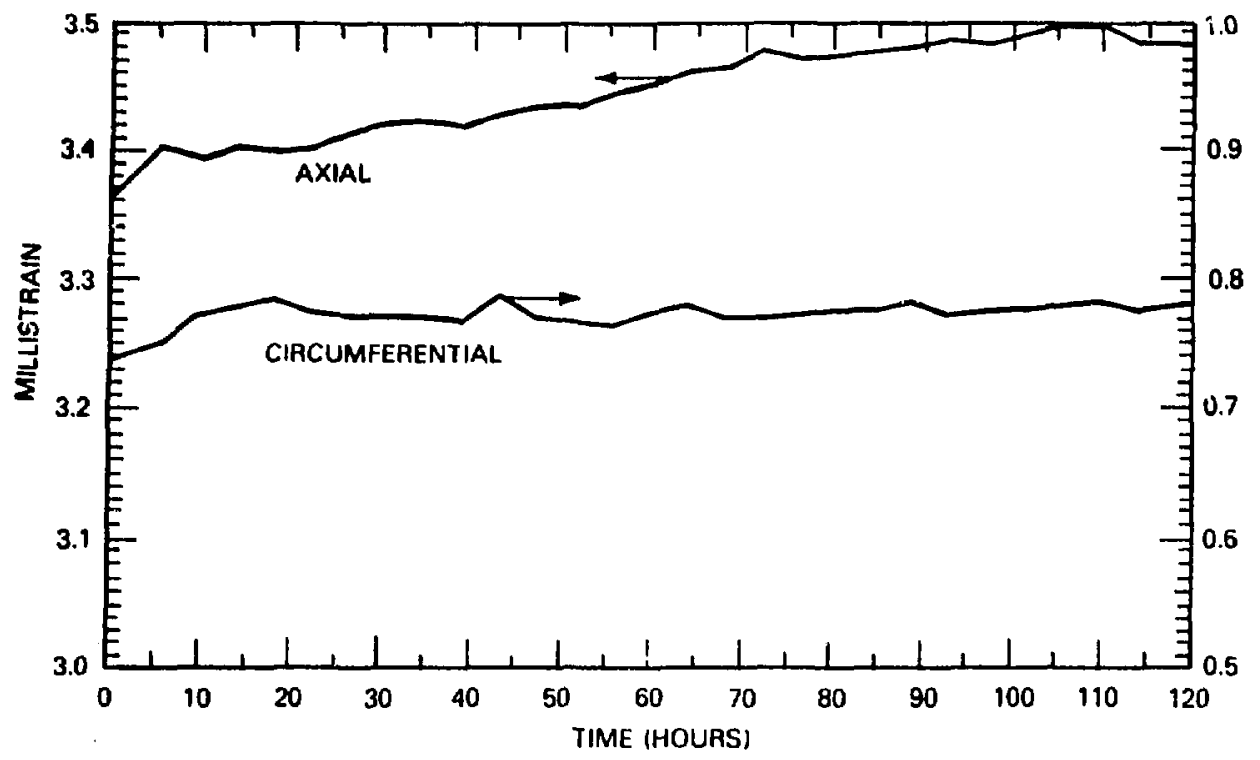

Fig. 8 .

Axial and circumferential creep strain vs time for Grouse Canyon welded tuff. Uniaxial stress is $75 \mathrm{MPa}$ and temperature is $25^{\circ} \mathrm{C}$.

resulted in unstable conditions and failure. In the case of the circumferential strain, which is the most sensitive indicator of crack formation in a uniaxial test, the strain increased from a stable level of $0.8 \times 10^{-3}$ to an unstable level of $1.1 \times 10^{-3}$ within 1 second after the $75-\mathrm{MPa}$ level was exceeded. The volume strain (axial minus twice the circumferential strain) at the end of the first loading was approximately $1.9 \times 10^{-3}$. The volume strain at the beginning of failure in the second loading was about $2.4 \times 10^{-3}$ and rapidly decreasing as a result of dilatant crack formation (Fig. 9). In retrospect, it appears that if the average strain rate in the first loading to $75 \mathrm{MPa}$ had been maintained for an additional $120 \mathrm{~h}$, the failure-onset strain would have been reached. Thus, onset of creep failure of this tuff under uniaxial conditions in a dry atmosphere at ambient temperature and pressure appears to occur over a narrow strain range with little indication of the nearness to the failure stress. Finally, examination of the sample did not reveal any pumice fragment or other weak zone in the interior that could have been responsible for the low fallure stress ( $\mathrm{g} 90 \mathrm{MPa}$ compared to $180 \mathrm{MPa}$ from the SNL data and the maximum values in Fig. 7). 


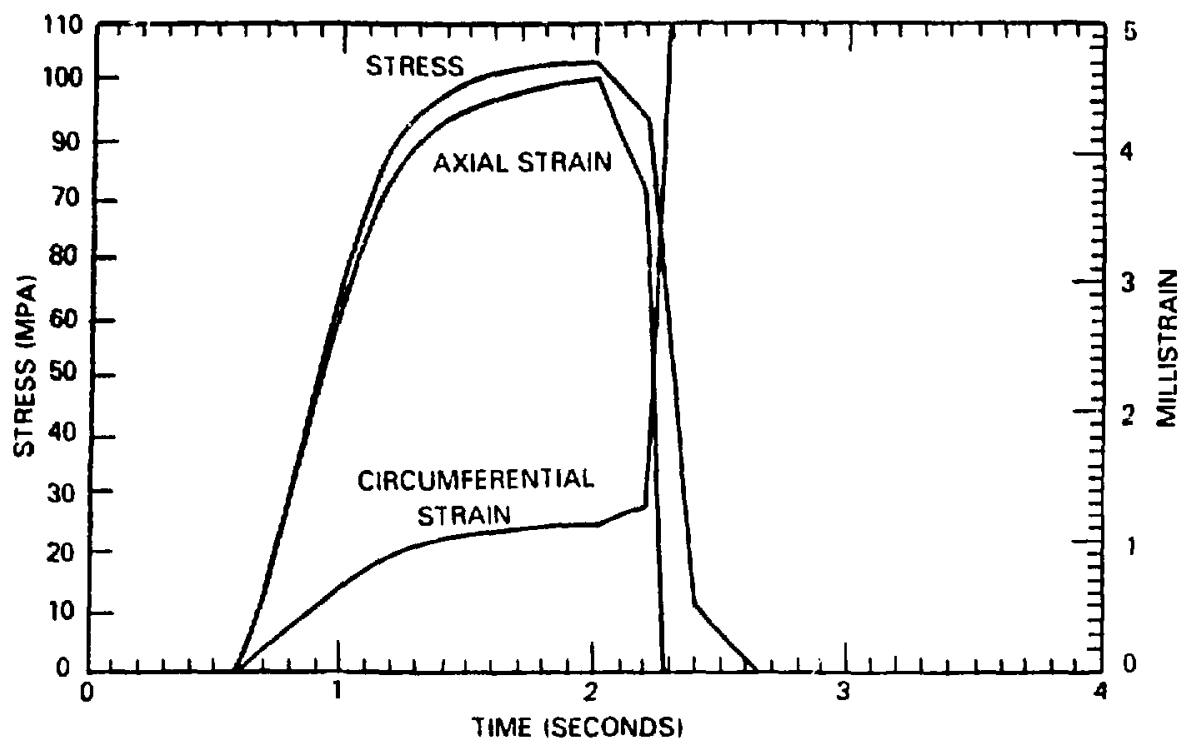

Fig. 9.

Uniaxial stress, axial strain, and circumferential strain vs time for same sample as in Fig. 8.

A third test was performed on a granite sample to test the confining pressure and temperature control systems. Granite was used instead of tuff because of the uncertainty in predicting the failure stress in tuff, as described above. We wanted to be certain that the sample would not fail during the check-out procedures. This test lasted approximately 3 weeks at $100^{\circ} \mathrm{C}, 10$ $\mathrm{MPa}$ confining pressure, and $100 \mathrm{MPa}$ differential stress. During this time, we tuned the temperature controller and attempted to control confining pressure. However, it was noted that small temperature variations $\left( \pm 1\right.$ to $\left.2^{\circ} \mathrm{C}\right)$ would cause unexceptable pressure variations $\left({ }^{n+} 10 \%\right)$ because of thermal expansion of the silicon confining pressure oil. As a result, we added the active confining pressure control that is described in Sec. II.B. With this device we are able to hold confining pressure to within $\pm 0.5 \%$ of the desired value regardless of temperature or other variations.

Following these preliminary experiments and the resultant tuning of the apparatus, we began testing potential target horizon rock under conditions expected in the near field of a repository. The first of these tests has been completed, and although the test was not completely successful because of a jacket leak, some interesting results were obtained. 
The test specimen was Bullfrog tuff from the 2483-ft level of hole USW-G1. The sample was $11.1 \mathrm{~cm}$ long and $5.4 \mathrm{~cm}$ in diameter. The test conditions were $100^{\circ} \mathrm{C}, 50 \mathrm{MPa}$ differential stress, $20 \mathrm{MPa}$ confining pressure, and $5 \mathrm{MPa}$ water pore pressure. The effective confining pressure of $15 \mathrm{MPa}$ was attained initially, but because a slow jacket leak developed early in the test, the effective pressure slowly dropped over the duration of the test to about $50 \%$ of its initial value. Because of the slow decrease in effective pressure, axial strain actually decreased slowly from the initial loading value while circumferential strain increased slowly (Fig. 10). Over the last $20 \mathrm{~h}$ of the test, the average circumferential strain rate was $\sim 1.2 \times 10^{-9} \mathrm{~s}^{-1}$, which increased very slightly in the last $2 \mathrm{~h}$. In retrospect, this almost imperceptible increase in strain rate was the onset of a type of Tertiary creep that only developed strongly in the last $200 \mathrm{~s}$ of the test. During this time, strain accelerated rapidly and the sample failed at a total test time of about $69 \mathrm{~h}$. Figure 10 shows the average of t:10 axial strain gauges away from the ultimate zone of failure (which apparentiy was also near the jacket leak because the gauge that failed showed a much greater decrease in strain over time). The increase in circumferential and volume strain at about $23 \mathrm{~h}$ corresponds to the time when the pore pressure accumulator was valved off, resulting in a transient increase in the rate of effective pressure decrease.

This type of sudden Tertiary creep failure is similar to that which was observed in uniaxial, room-temperature creep of Grouse Canyon welded tuff. In each case there has been little indication of the nearness to failure, and so far there is no evidence of the classical, exponentially increasing Tertiary creep that has been observed in granite and other materials. This may be a reflection of the structural inhomogeneity of our tuff samples in which failure may start in a very local region with no general increase in microfracturing activity that might be noticeable at strain gauges outside of the ultimate failure zone.

Although this test alone does not establish a new issue of concern, it does suggest a type of potential failure that should be evaluated. In the near field of a repository, in a material of very low permeability and relatively high water content such as a zeolitized tuff, thermal expansion of pore water or mineral dehydration water could lead to a local increase in pore pressure if the water could not leak away rapidly enough. This could lead to local rock failure initiation because of the reduction in effective pressure. 


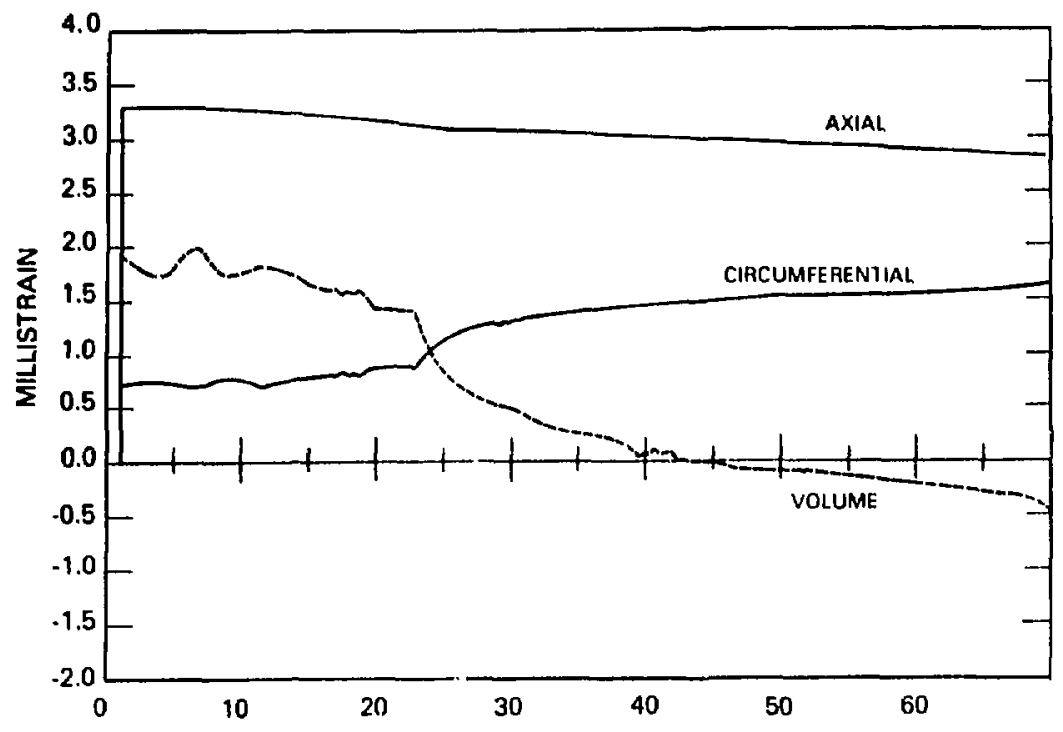

TIME (HOURS)

Fig. 10.

Axial, circumferential, and volume strain vs time for Bullfrog tuff experiment. Compression is positive, but the sign of the circumferential strain is reversed in the plot. Tests were performed at $100^{\circ} \mathrm{C}, 20 \mathrm{MPa}$ confining pressure, 5 to $12.5 \mathrm{MPa}$ pore pressure, and $50 \mathrm{MPa}$ differential stress.

This would occur while at least some of the strain monitors were indicating a decreasing rate of strain because of the overall decompression associated with a falling effective pressure (analagous to the axial strain record in Fig. 10).

\section{CONCLUSIONS AND STATUS}

We have designed and perfected an apparatus capable of performing precise, long-term creep deformation tests on rock samples. The apparatus is capable of performing tests lasting several months at maximum differential stress of $970 \mathrm{MPa}$, confining pressure of $1200 \mathrm{MPa}$, pore pressure of $40 \mathrm{MPa}$, and temperature of $250^{\circ} \mathrm{C}$. A system for measuring sample permeability under the above conditions has been designed but remains to be completed and tested.

Grouse Canyon welded tuff has a uniaxial compressive strength inhomogeneity of at least a factor of three on a scale of a few centimeters. Note that we are considering only "intact" samples not containing larger scale inhomogeneities such as joints, fractures, or lithophysae. If target horizon tuffs show a similar inhomogeneity, then many more tests will have to be performed 
than originally anticipated to get good statistics on mechanical properties, or larger samples containing a representative number of inhomogeneities will have to be tested. Probably both approaches will be required.

The onset of microclastic creep fallure in Grouse Canyon welded tuff at ambient conditions and Bullfrog tuff at $100^{\circ} \mathrm{C}, 15$ to $7.5 \mathrm{MPa}$ effective pressure, and $50 \mathrm{MPa}$ differential stress appears to occur over a narrow strain range with little Tertiary creep warning. In one test of Bullfrog tuff under conditions of slowly decreasing effective pressure, a failure occurred; during the failure, some strain gauges actually indicated a decreasing rate of strain, which was caused by the overall decompression of the sample.

\section{REFERENCES}

1. J. D. Blacic, "Importance of Creep Failure of Hard Rock in the Near Field of a Nuclear Waste Repository," Los Alamos National Laboratory document LA-UR-81-2584 (1981).

3. J. Blacic, J. Carter, P. Halleck, P. Johnson, T. Shankland, R. Andersen, K. Spicochi, and A. Heller, "Effects of Long-Term Exposure of Tuffs to High-Level Nuclear Waste-Repository Conditions: Preliminary Report," Los Alamos National Laboratory report, in preparation.

3. W. R. Wawersik, "Technique and Apparatus for Strain Measurements on Rock in Constant Confining Pressure Experiments," Rock Mech. 7, 231-241 (1975).

4. W. F. Brace, J. B. Waish, and W. T. Frangos, "Permeability of Granite Under High Pressure," J. Geophys. Res. 73, 2225-2236 (1968).

5. W. A. 01 sson and A. K. Jones, "Rock Mechanics Properties of Volcanic Tuffs from the Nevada Test Site," Sandia National Laboratories report SAND80-1453 (1980). 


\section{APPENDIX}

FORTRAN LISTING OF CONTROL AND DATA ACQUISITION PROGRAM

Los Alamos Identification No. LP-1465

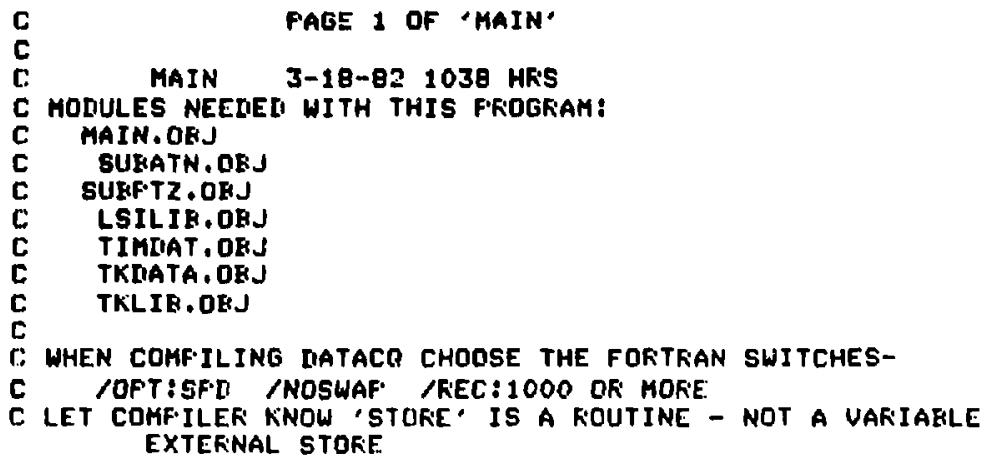

C

c.

C

IIATA IX, IYO/1295, 1295, 32*1560/

IIATA IISFI.AG/AHFLAG, AH CHA. AHNNEL, 12*AH

IIATA KEUENT, LEVENT $/ 0.0 /$

IIATA IE:IJF/1000*0/

IIATA NOGRF'H/1/

[IATA JUPIK/19190/

IIATA JUNK, JUNKK/19190,19191,19192,19193,19194,19195/

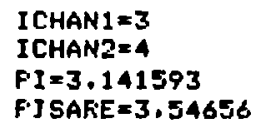

C !! WE IION'T KNOW WHY, EUT IIO THIS FIRST

CALL ASSIGN (ICHAN2, 'IIY1:EXFTII,ATA',13, 'NEW', ,2) KEWINI ICHAN2

TYF'E 211

211 FOFMAT ( $/$ IO YOU WISH TO CKEATE A RESTART FILE (Y OK N) ?', ACCEFT 2300 . ANSW

c.

CALL CLOSE (I CHAN1)

C 


\section{APPENDIX (cont)}

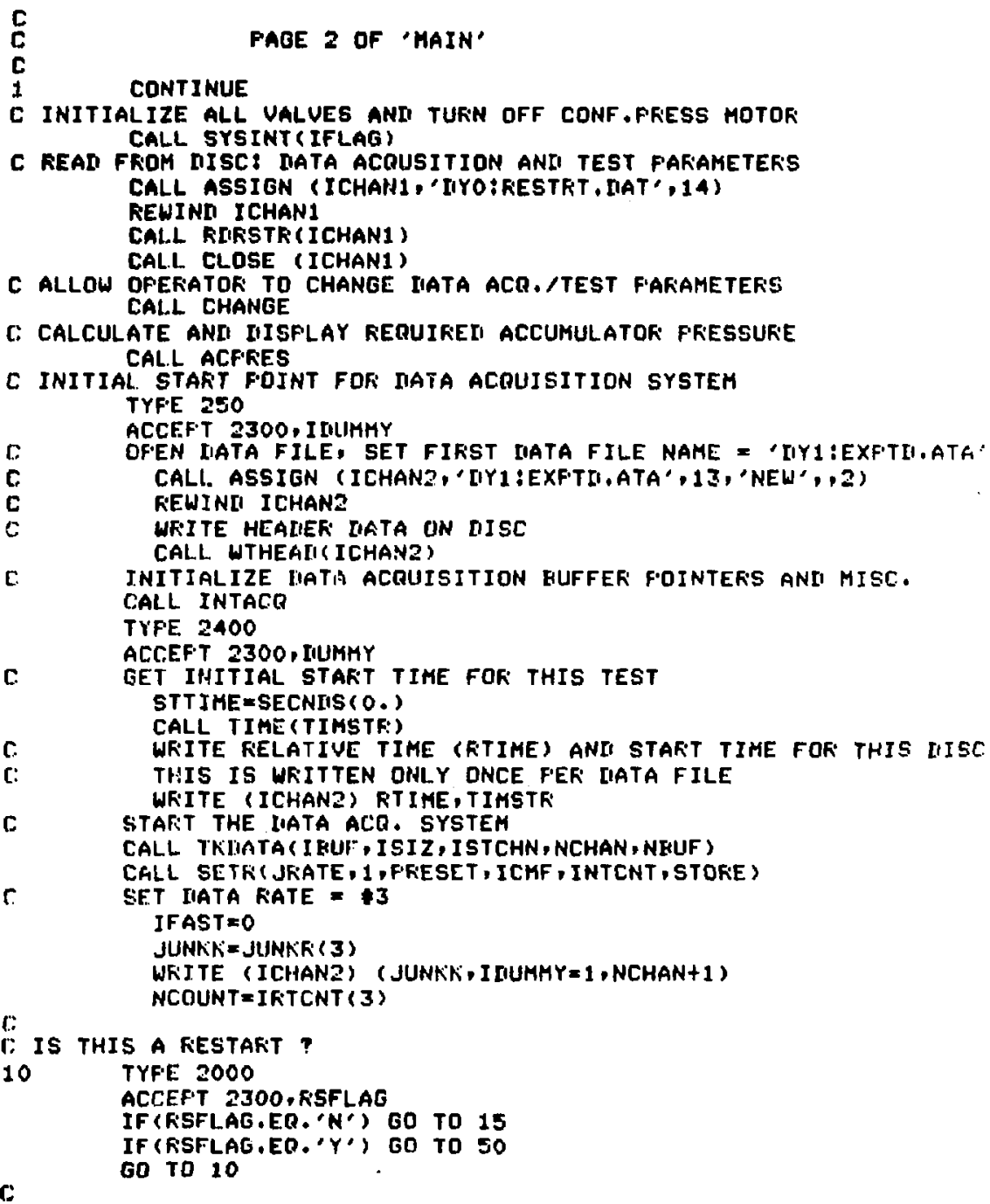




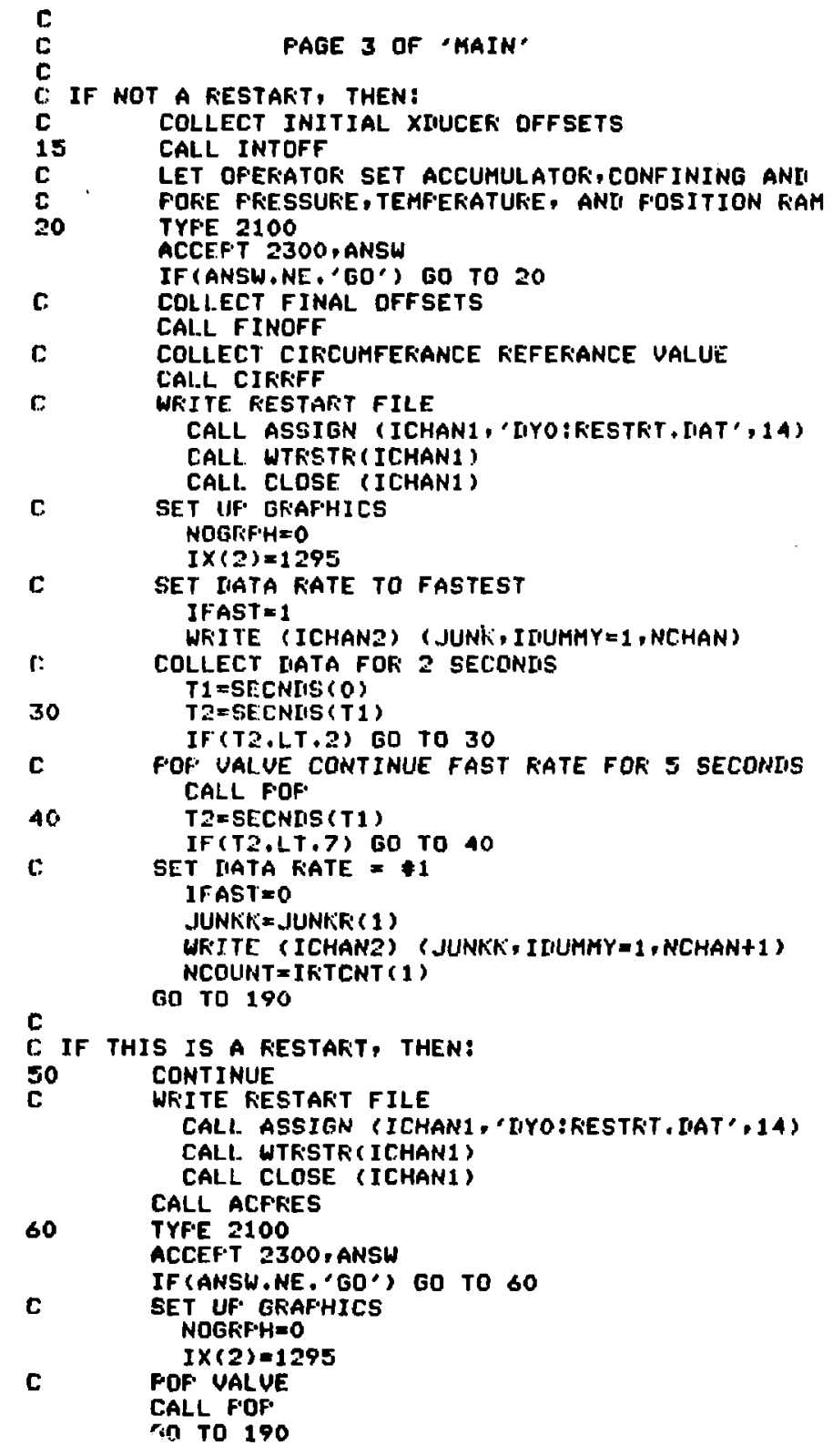




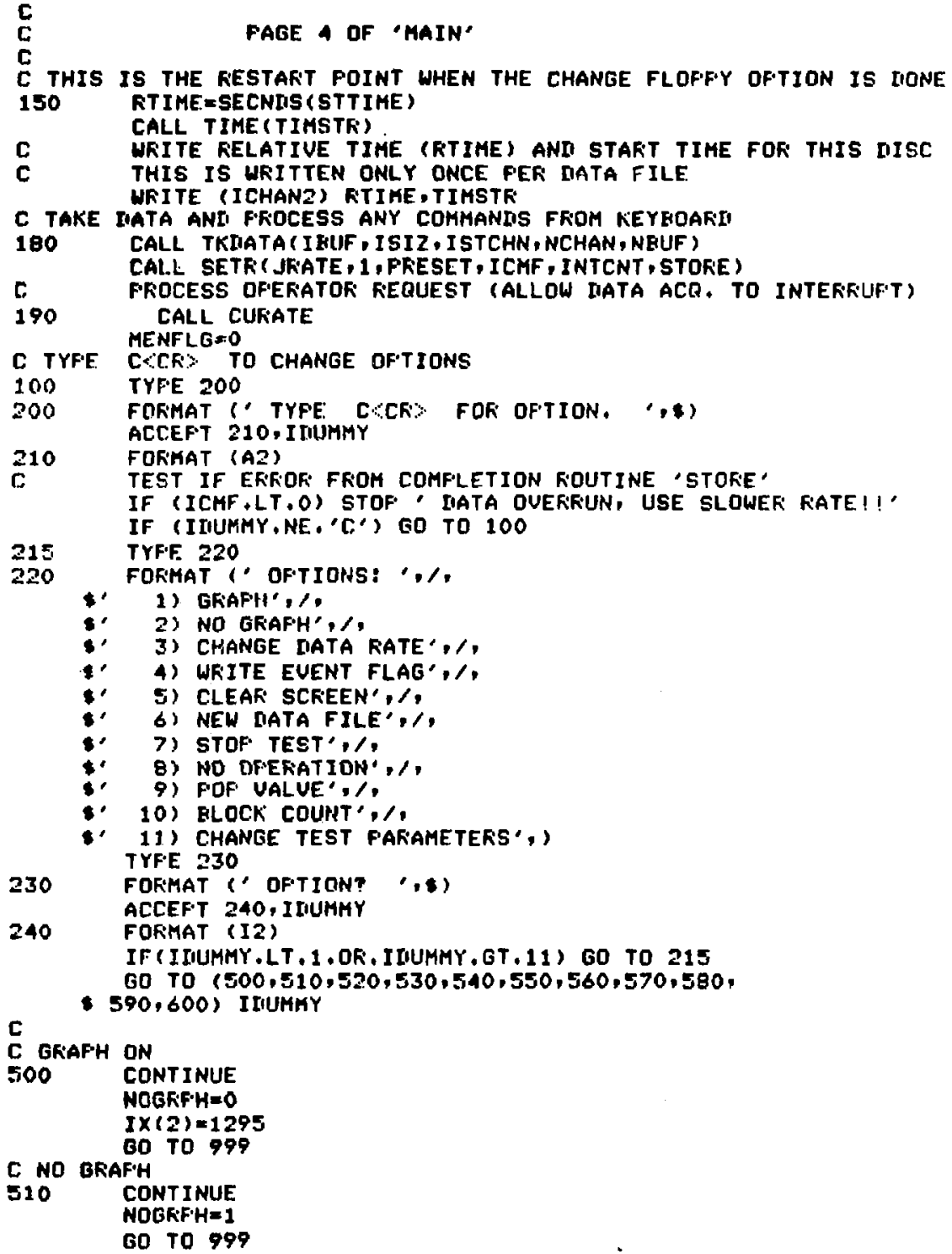




\section{APPENDIX (cont)}

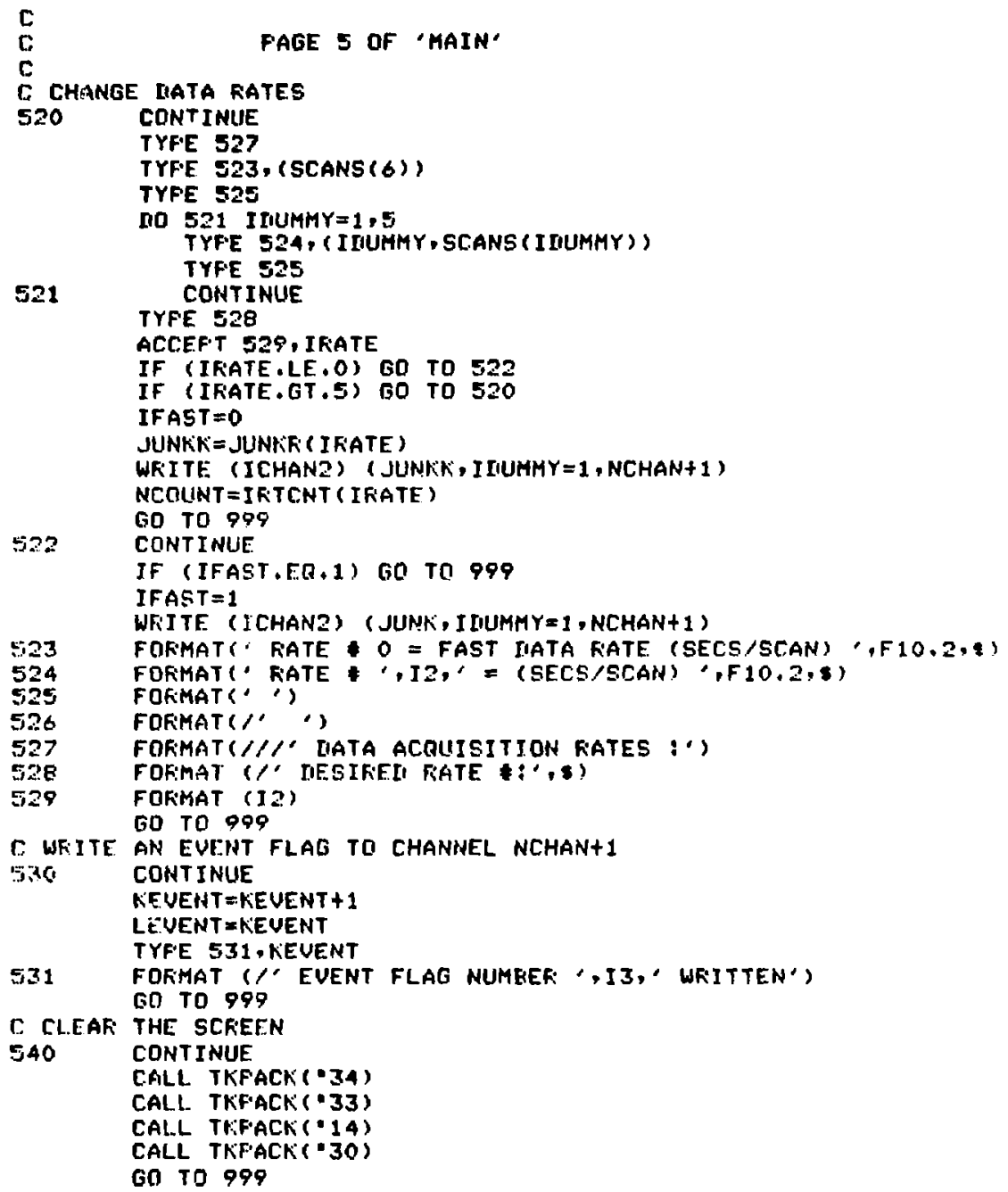




\section{APPENDIX (cont)}

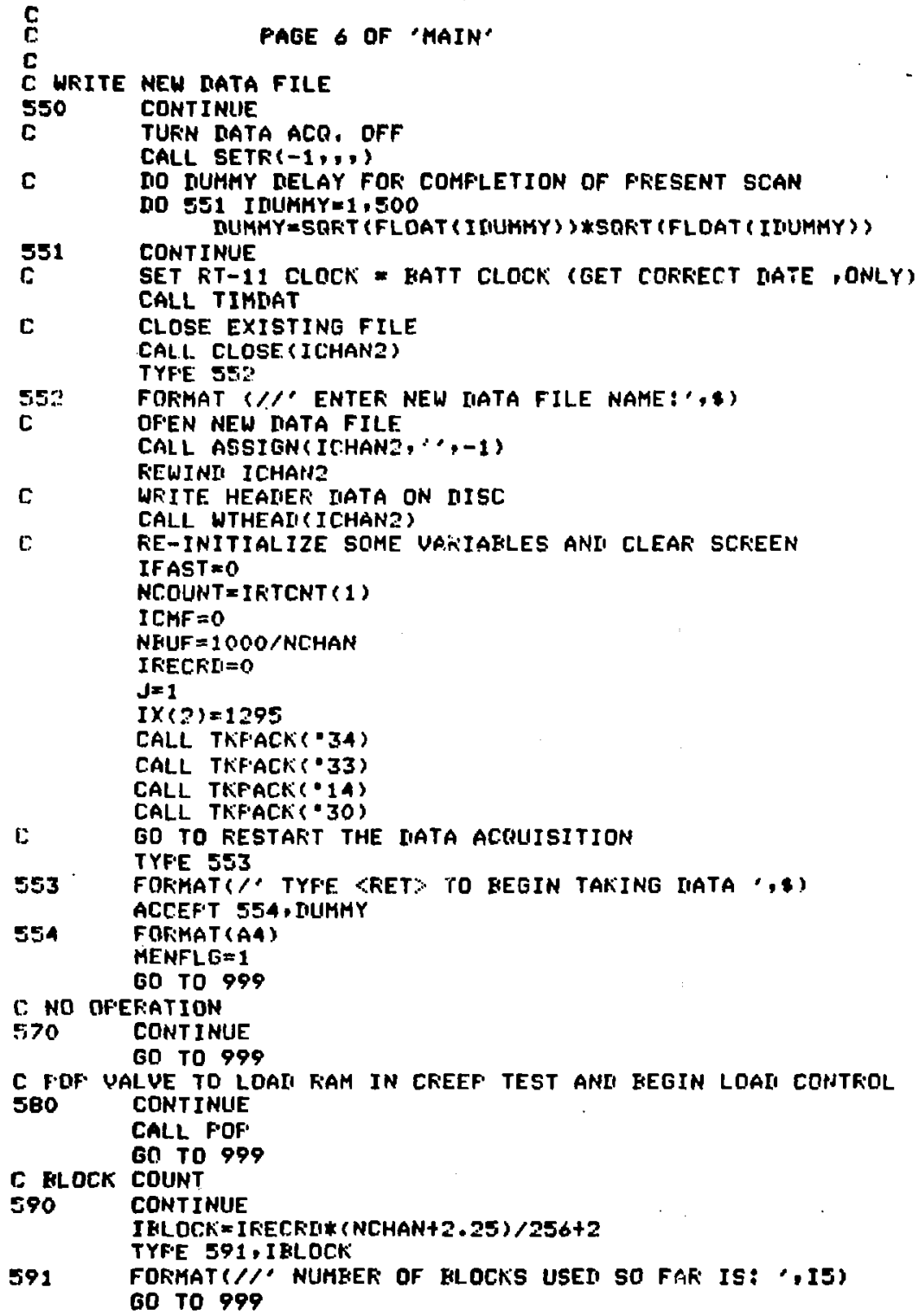




\section{APPENDIX (cont)}

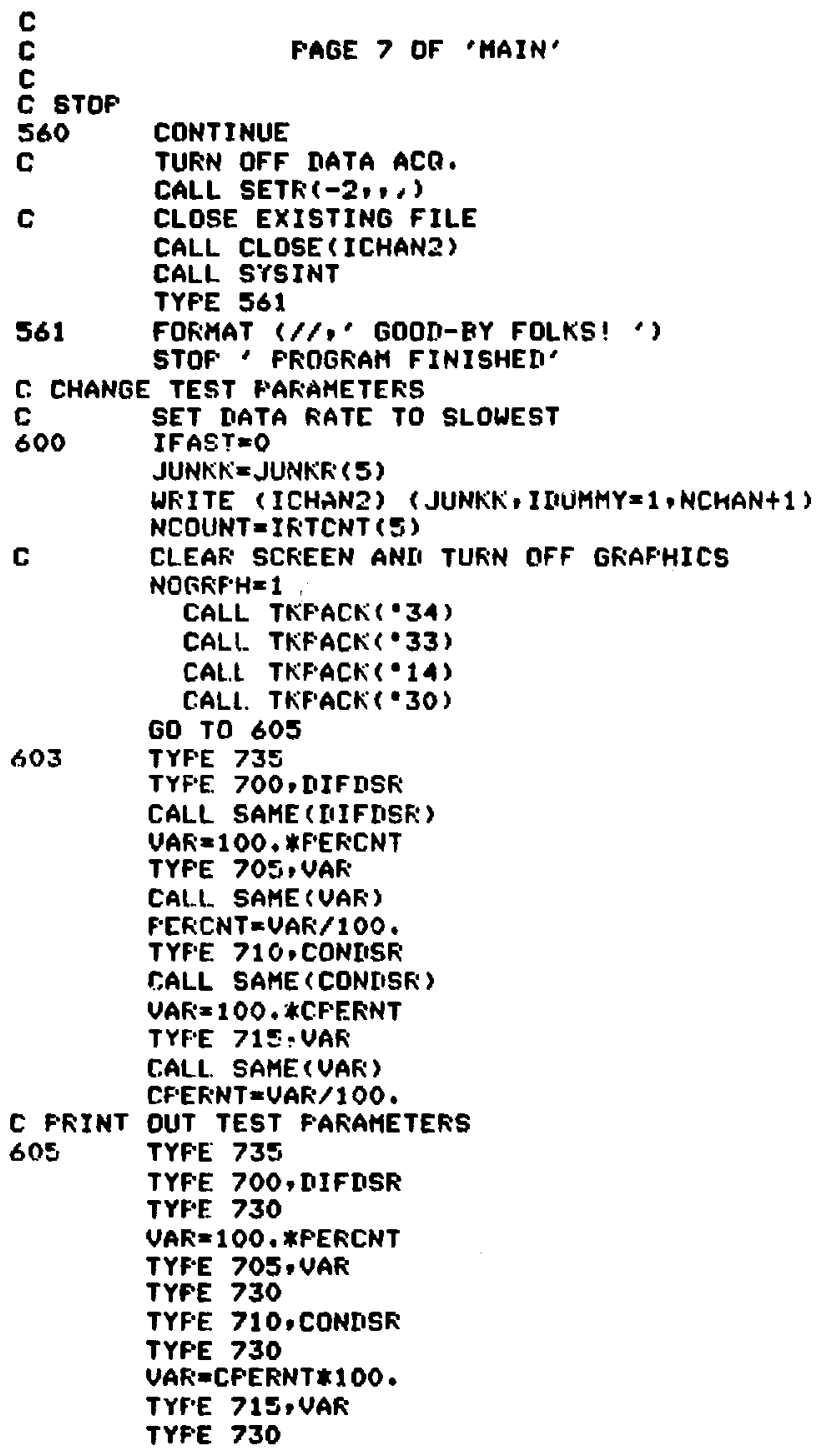




\section{APPENDIX (cont)}

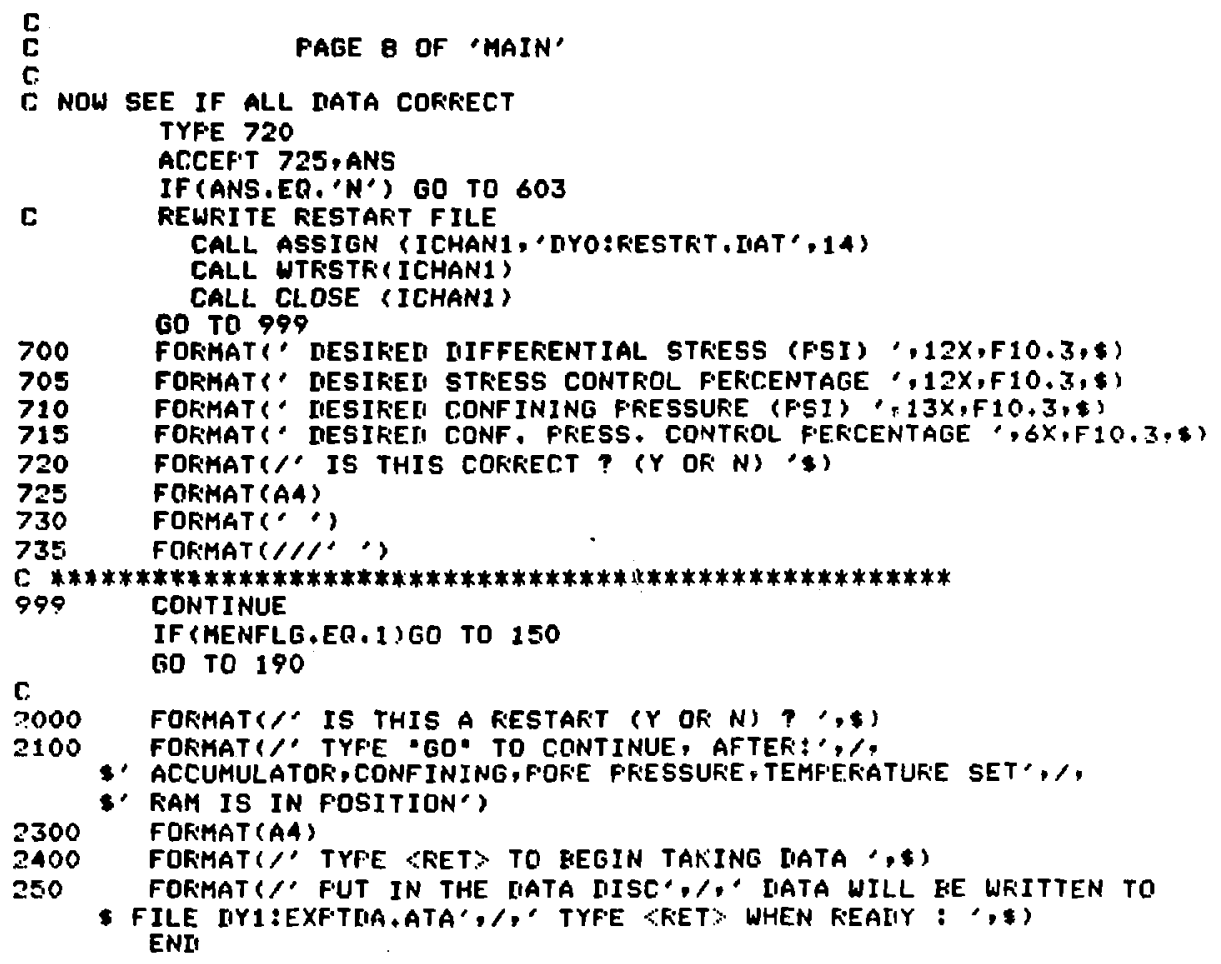

c

c

C NOW SEE IF ALL DATA CORKECT

TYFE 720

ACCEF'T 725 , ANS

C IF (ANS.EQ.'N') GO TO 603

C REWRITE RESTART FILE

CALL ASSIGN (ICHAN1, 'DYO:RESTRT, IIAT', 14)

CALL WTKSTR (ICHAN1)

CALL CLOSE (ICHANI)

700 FOFMAT?' DESIFED IIIFFERENTIAL STKESS (FSI) $, 12 \times, F 10,3, \$$ )

705 FORMAT\&' DESIREI STRESS CONTROL FERCENTAGE ',12X,F10.3,,

710 FORMAT " DIESIREI CONFINING FRESSURE (FSI) $, 13 \times, F 10,3, \$)$

715 FOFMATS" DESIREY! CONF, FRESS , CONTROL FERCENTAGE',6X,F10,3,\$)

720 FORMAT (/ IS THIS CORKECT ? (Y OK N) ' 1

725 FORMAT (AA)

730 FORMAT:"

735 FOFMAT (///, ')

c $* * * * * * * * * * * * * * * * * * * * * * * * * * * * * * * * * * 1 k * * * * * * * * * * * * * * * * * *$

999 CONTINUE

IF (MENFLG,EQ, 1$) G O$ TO 150

c. GO TO 190

3000 FORMAT $/$, IS THIS A RESTAFT (Y OF $N$ ) ? ',

2100 FORKAT $\%$ TYFE = GO" TO CONTINUE, AFTER:",

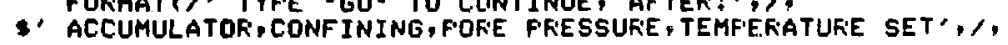

- RaM is IN fOSITION')

2300 FORMAT (A4)

2400 FOFMAT $\%$ TYFE «RET> TO GEGIN TAKING IIATA '\$)

250 FORMAT $/ \%$ FUT IN THE IIATA DISC* $/ \%$ IIATA WILL EE WFITTEN TO

\$ FILE IIY1:EXF'TIA,ATA', ," TYFE (RET, WHEN FEAIIY : , ENI 


\section{APPENDIX (cont)}

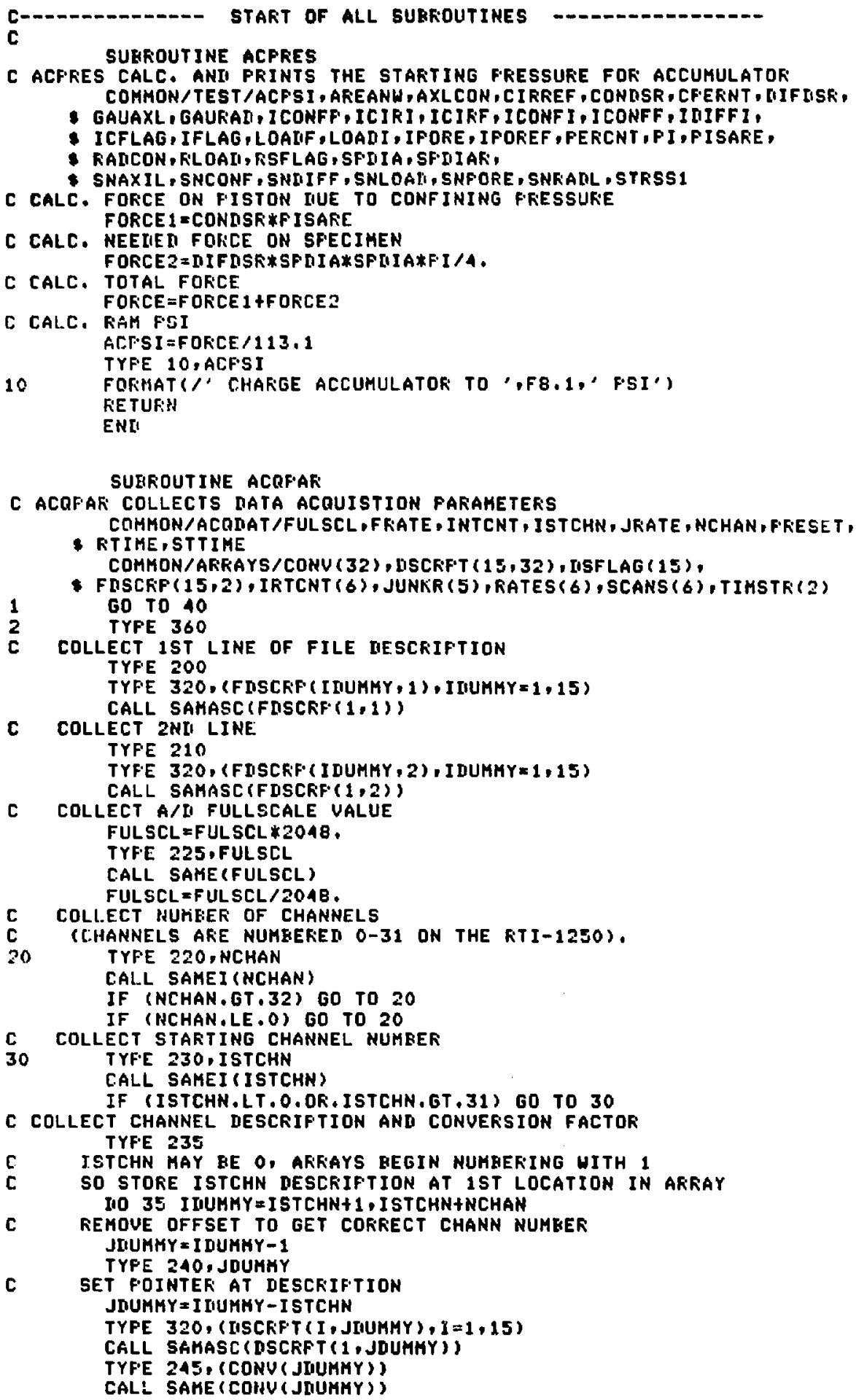


APPENDIX (cont)

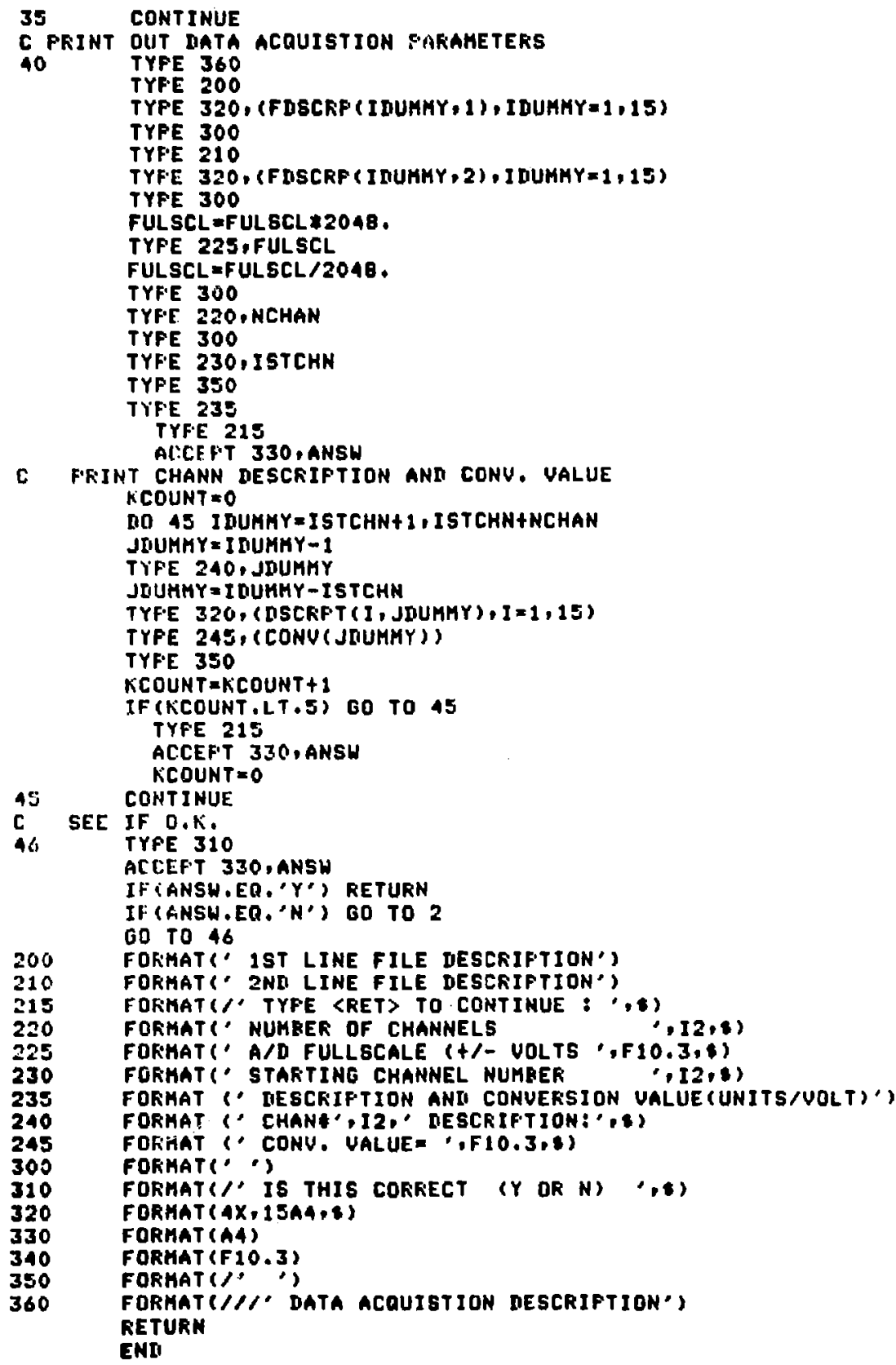




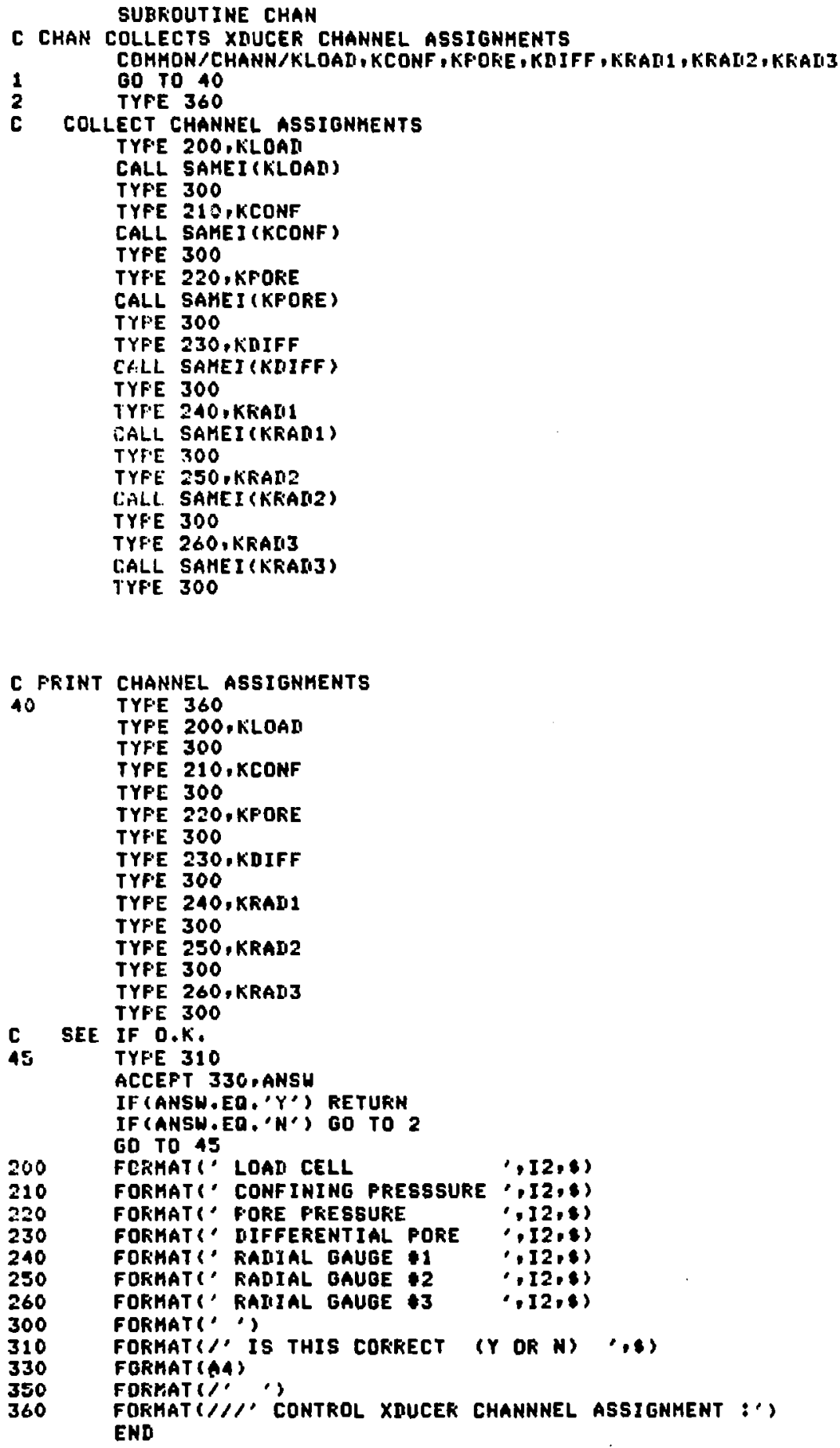


APPENDIX (cont)

SUBRDUTINE CHANGE

C CHANGE ALLOWS OFEKATOK TO CHANGE DATA ACR,/TEST FAF'AHETERS

CALL CHAN

CALL PARAM

CALL ACQPAR

CALL DATKAT

RETURN

ENII

SUEKOUTINE CIRKFF

C CIRRFF CALC. REFERANCE STRAIN A/D UNITS, SFEC,DIA/CIFCUM AFTER THE

C APPLICATION OF CONFINE/FORE PRESS AND TEKF

C ENTER SFDIA=INIT, SFECHEN DIA. IN,. ICIRI=INIT,STFAIN A/I UNITS

C EXIT REF, VALUES: SFDIAK=DIA, (IN,), CIRKEF =CIRCUM, (IN,),ICIRKF =STRAIN(A/D) COMMON/FROCES/IBUF $(1000)$, NEUF, ISIZ, NCOUNT,

- IFAST I ICHAN I , ICHAN2, J, NOGRFH, IYO (16), IX (2), LEVENT, IRECED

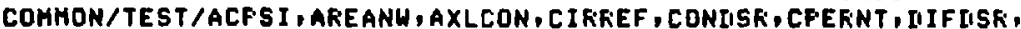

- GAUAXL, GAURAD, ICONFF, ICIRI, ICIRF, ICONF I, ICONFF, IDIFF I,

- ICFLAG , IFLAG , LOALIF , LOALI, IFOKE, IF OKEF, FEFCNT , FI , PI SARE,

- RaDCon, Rload, RSFLag, SFDia, SPIIAR.

- SNAXIL, SNCONF, SNIUIFF, SNLOAI, SNFOKE, SNRAIIL, STKSSI

C MEASURE ALL 3 RADIAL GAUGES,FINI AUG, $A / D$ UNITS

I IIATA1 = I BUF ( (J-ISTCHN) + KRADI)

IIIATA2 = I BUF ( ( J-ISTCHI) +KKAL2)

I IATA $3=$ I BUF ( ( J-ISTCHN) +KFA[13)

IAUG = (I DATA1 + I DATA2 + I [/ATA3) /3

C. CAL.C. IIELTA A/D LIHITS USING NO TERF/F'RESS VALUE DELTA I I AVG - I I IRI

C CALC.EFSLON, CONUEFT FROM MILLISTFAIN TO STRAIN EFSLON= [IELTA*R:ADCON/1000.

C. CALC, NEW IIJAHETEK

SFIIIAK $=5 F[D I A *(1+E F$ SLON $)$

CIKREF $=S F I I$ IAR*FI

RETURN

ENI 
APPENDIX (cont)

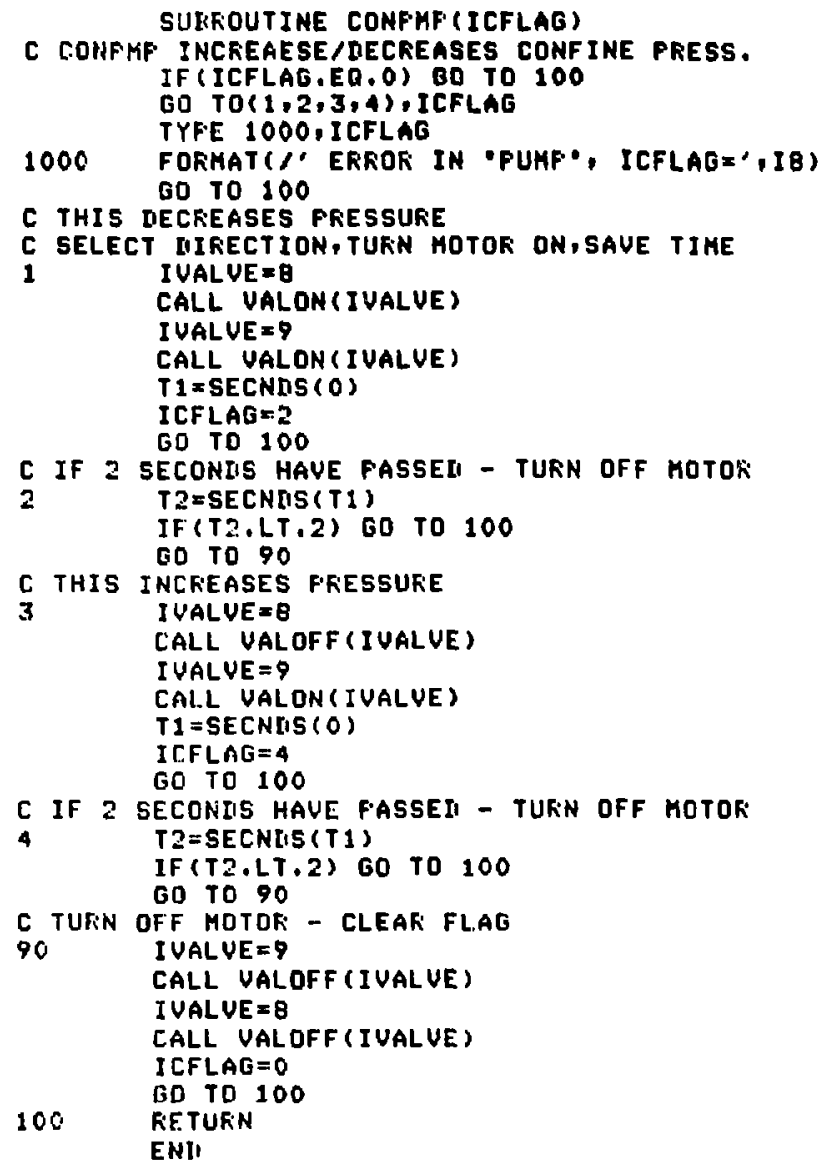




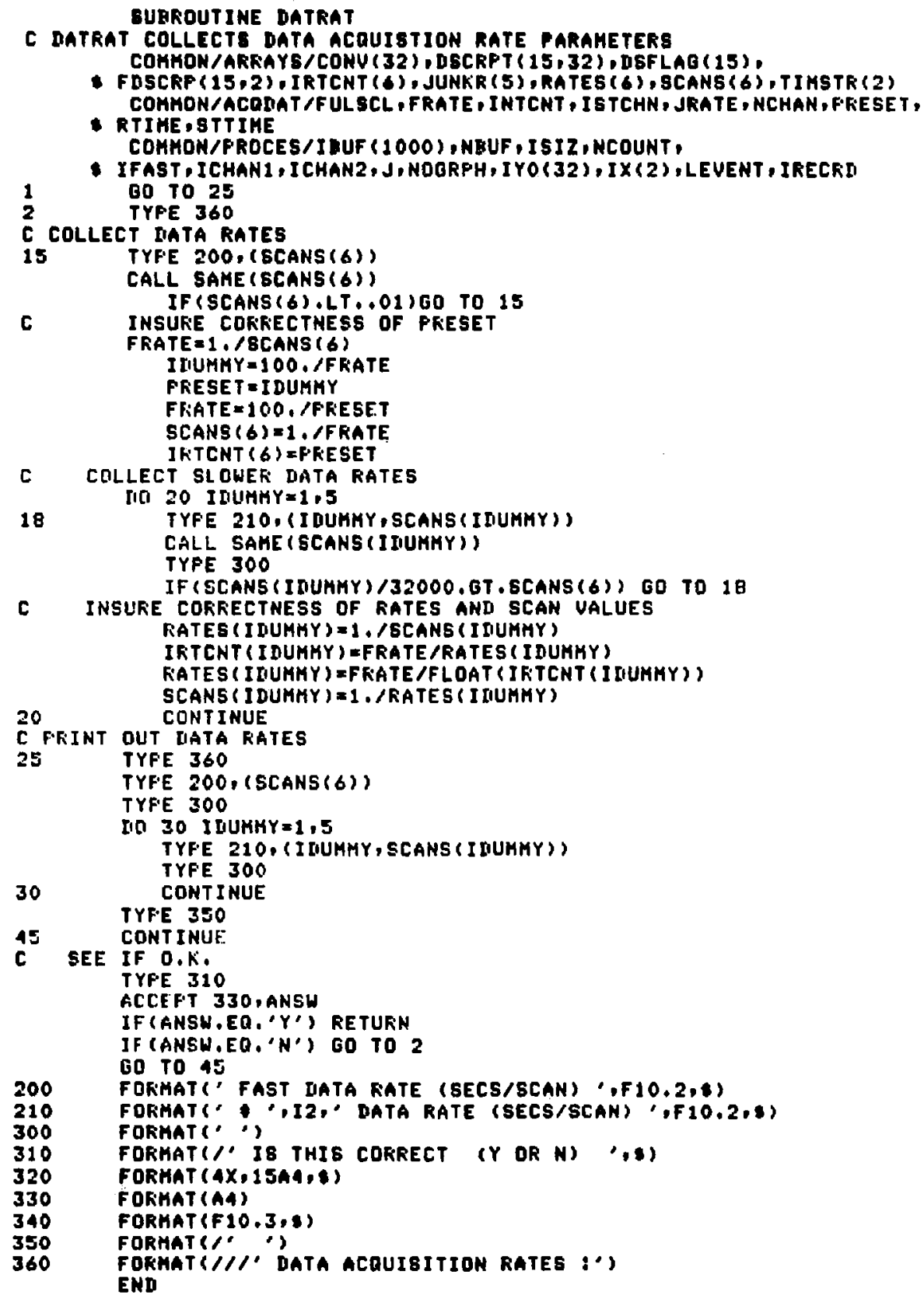


SUBROUTINE FINDFF

C FINOFF COLLECTS XDUCER OFFSET (A/D UNITS) AFTER TEMF/FRESS SET COMMON/CHAMH/KLOAD, KCONF, KPORE , KDIFF, KRAD1, KRAD2, KRAD3 COMMON/FROCES/I BUF (1000), NBUF, ISIZ, NCDUNT,

- IFAST, ICHAN1, ICHAN2 J, NOORFH, IYO (32), IX $(2)$, LEUENT , IRECRL COHMON/TEST/ACPSI, AREANW, AXLCON, CIRREF, CONUSR, CFERKT, IIIFISF,

* GAUAXL, GAURAD, I CONFF, ICIRI, ICIRF, ICONF I, ICONFF , IDIFF I,

- ICFLAG , IFLAG , LOADF, LOADI, IFORE, IFOREF , FERCNT, PI , FISARE,

- RADCON, RLDAD, RSFLAG, SFIIIA,SFDIAR.

- SNAXIL, SNCONF, SNIIFF, SHLOAD, SNFOKE, SHRAIIL, STRSS1

LOADFEI RUF ( ( $J-I S T C H N)+K L O A D)$

ICONFF = I EUF ( $(\mathrm{J}-I S T C H N)+K C O N F)$

IPOREF $=$ IBUF ( ( J-ISTCHN $)+K F O R E)$

C MEASUKE ALL 3 KALIIAL GAUGES IFINII AUG. IIATA1 = I EUF ( (J-ISTCHN ) +KRADI) IIIAT A2 = IEUF ( (J-ISTCHN ) +KRAII2) I DATA3 = I EUF ( (J-ISTCHN ) +KKA[13) ICIKF = ( I IIATAI I ISATA2+IDATAB )/3 RETURN ENII

SURFOUTINE GRIIVE

C DRAW CKUDE GRIII ANII FRINT VARIABLE LABELS

LOGICAL*1 CAN, SUE,ESC,FS,GS,US, DEL, ITTLA,FF

LOGICAL*1 ISTRS(15)

LDGICAL*1 OLISTK(15)

LOGICAL*1 LABSTK(7)

C

DIMENSION KHAR(10)

C

DIMENSION IY(2), IXX(2)

COMHON/FFOCES/I BUF ( 1000$)$, NBUF, ISIZ, MCOUNT,

- IFAST, ICHAN 1, ICHAN2, J, NOGRPH IYO (32), IX (2), LEUENT , IRECKII COMHDN/SCKEEN/KDISP, I RLOAD, IOTEHF, RONST 1, RONST2, RTEKF COHMON/TEST/ACFSI , AREANW , AXLCON, EIRREF, CONUSR , CFERNT, UIF ISF,

- GAUAXL , GAURAD, I CONFF, ICIRI, ICIRF, I CONF I, I CONF , I IIFF I,

- ICFLAG , IFLA , LOAIF , LOADI, IFORE, IFOREF, FERCNT , PI, PISARE,

- Rancon, RL oali, RSFLag, SFII , SFIIIAK,

- SNAXIL, SNCONF, SNDIFF, SHLOAD, SNFORE, SNRAIL , STRSS1

C

IIATA IXX/1295, 1095/

IIATA CAN, SUB,ESC,FS, GS,US, DEL, LITTLA/・30, 32, $33, \cdot 34, \cdot 35, \cdot 37$, 8.177,:141/

DATA FF/.14\%

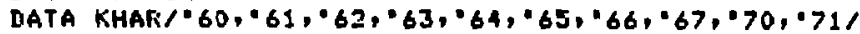

IIATA ICOUNT/1/

DATA LABSTR/1HS, 1HT, IHF, IHE, IHS, 1 HS, $1 \mathrm{H}=/$

C

CLEAR SCREEN

GO TO POINT MOIE

CALL TKFACK(FE)

C GO TO 4010 ALFHA,CLR SCREEN, DATA×WHITE,HOHE CURSOR

CALL TKPACK(ESC)

CALL TKFACK(FF)

C 60 TO ADH-3 ALFH

CALL TKFACK(CAN)

C -FULL SCALE LINE

c GO TO VECTOK MODE

CALL TKFACK(OS) 


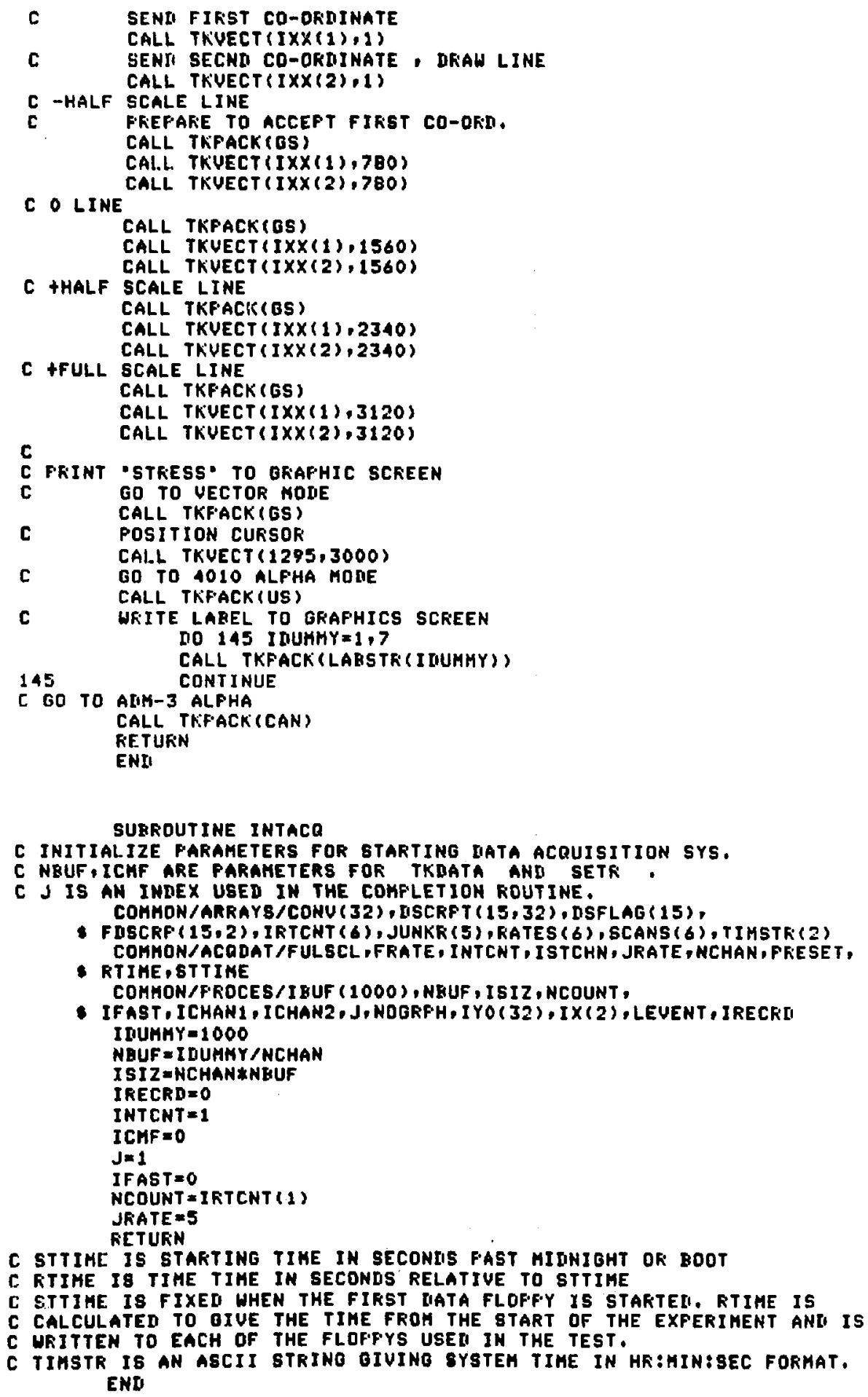


SUBROUTINE INTOFF

C INTOFF COLLECTS INITIAL DFFSET A/D UHITS FOR VARIDUS XDUCERS COMMON/CHANN/KLOAD , KCONF , KPORE , KDIFF , KRADI , KRADZ , KRALI COMHON/FROCES/I BUF (1000), NEUF, I I 2 , NCOUNT,

- IFAST, ICHAN 1, ICHAN2, J,NOGRFH, IYO (32), IX (2), LEVENT , IRECRD COHKON/TEST/ACFSI IAREANH, AXLCON, CIRREF, CONIISR, CPERNT, IIIFISR,

- GAUAXL , GAURAD, ICONFF, ICIRI , ICIRF, ICONF I , ICDNFF, I IIIFF I,

- I CFLAG IFLAG, LOAJF , LOAII, IFOKE, I FOKEF , FERCNT , FI , PISARE,

- RAICON, RLDAD, RSFLAG, SFDIA, SFIIIAR,

C

- SNAXIL, SNCONF, SNDIFF , SNLDAII, SNFORE, SNRADL, STRSS1

C GET INIT, VALUES FOR LDAD CELL, CONFIN ANLI FORE XIUCERS, KAIIAL GAUGES GET INIT. UALUES FDR LOAP CELL(LDAII)

1 LOALI = I KUF ( ( J-ISTCHN ) +KLDAL) I IUUMYY =KLDAI IF (IAES(LOALI), GT.Z) GO TO 1020

C GET INIT. VALUES FOR COHFINING PRESSURE (ICONFI) I CONF I I I RUF ( $(J-I S T C H N)+K$ CONF ) I IUMKY $=K$ CONF IF (IAES(ICONFI).GT . 2$)$ GO TO 1020

C GET INIT, UALUES FOR PORE PRESSURE (IFORE) IFORE = I EUF ( (J-ISTCHN $)+K F \cdot$ ORE $)$ I IUUMY $=$ KFOFE IF (IAES (IFDRE) . GT . 2) GD TO 1020

C GET INIT + UALUES. FOR RAIIIAL GAUGES (CIRIN)

C MEASUIFE ALL 3 FALIIAL GAUGES, FINI AUG, SAVE IN A/II UNITS I IIATA I = IEUF ( ( J-ISTCHN) +KKAIII) I IUMMY $=$ KFALI IF(IAES(IIIATA1), ET,2) GO TO 1020

I LATA2 = I BUF ( (J-ISTCHN ) +KRAD2) I IUMMY $=$ KKRAII2 IF (IAES(IIATA2), GT.2) GO TO 1020

I DATA I I IUF ( ( J-ISTCHN ) +KRADZ )

IIUMHY = KRAII3

IF (IAIS(IDATA3), GT.2) GO TO 1020

ICIFI $=$ ( IIIATA1 + IIIATA2 + IIIATA3) $/ 3$

RETURN

1020 TYFE 1025, IDUMMY

1025 FOKMAT(I' ALJUST ZERO ON CHANNEL ',I2,", THEN HIT (KET', '\$

1030 FDFHAT (A4) GO TO 1 ENI!

C MENUE PROCESSES OFERATOR REQUESTS COMHON/ACQDAT/FULSCL , FRATE, INTCNT , ISTCHN, JRATE , NCHAN, FRESET,

- RTIME, STTIME COKMON/ARKAYS/CONU(32), DSCKFT (15,32), IISFLAG (15),

- FDSCRP (15,2), IRTCNT (6), JUNKR (5), RATES (6),SCANS (6), TIKSTR (2) COMHOH/PROCES/IEUF (1000), NEUF, ISIZ, NCOUNT,

- IFAST I ICHAN 1 , ICHAN2, J, NOORFH,IYO $(32), I X(2)$,LEUENT , IRECRE COMMON/TEST / ACFSI, AREANW , AXLCON, CIRREF, CONLISR , CFERNT, IIIF IISR, - GAUAXL, GAURAI, I CONFF, ICIR I, ICIFF, ICONF I, ICONFF, IDIFFI,

- ICFLAG, IFLAG , LDAIIF, LOAII , IFOKE , IFOREF, FERCNT , PI , FISARE,

- RADCON, RLDali, RSFLAG, SFIIIA, SFDIAR,

$\mathbf{C}$

- SNAXIL, SNCONF, SNIIFF , SNLDAII, SNFORE , SNRAIL , STRSS1

MENFL G $=0$

C TYFE CSCK? TO CHANGE OFTIONS

100 TYFE 200

200 FORMAT (' TYFE C〈CK $>$ FOR OFTION, ',

210 FORMAT (A2) 


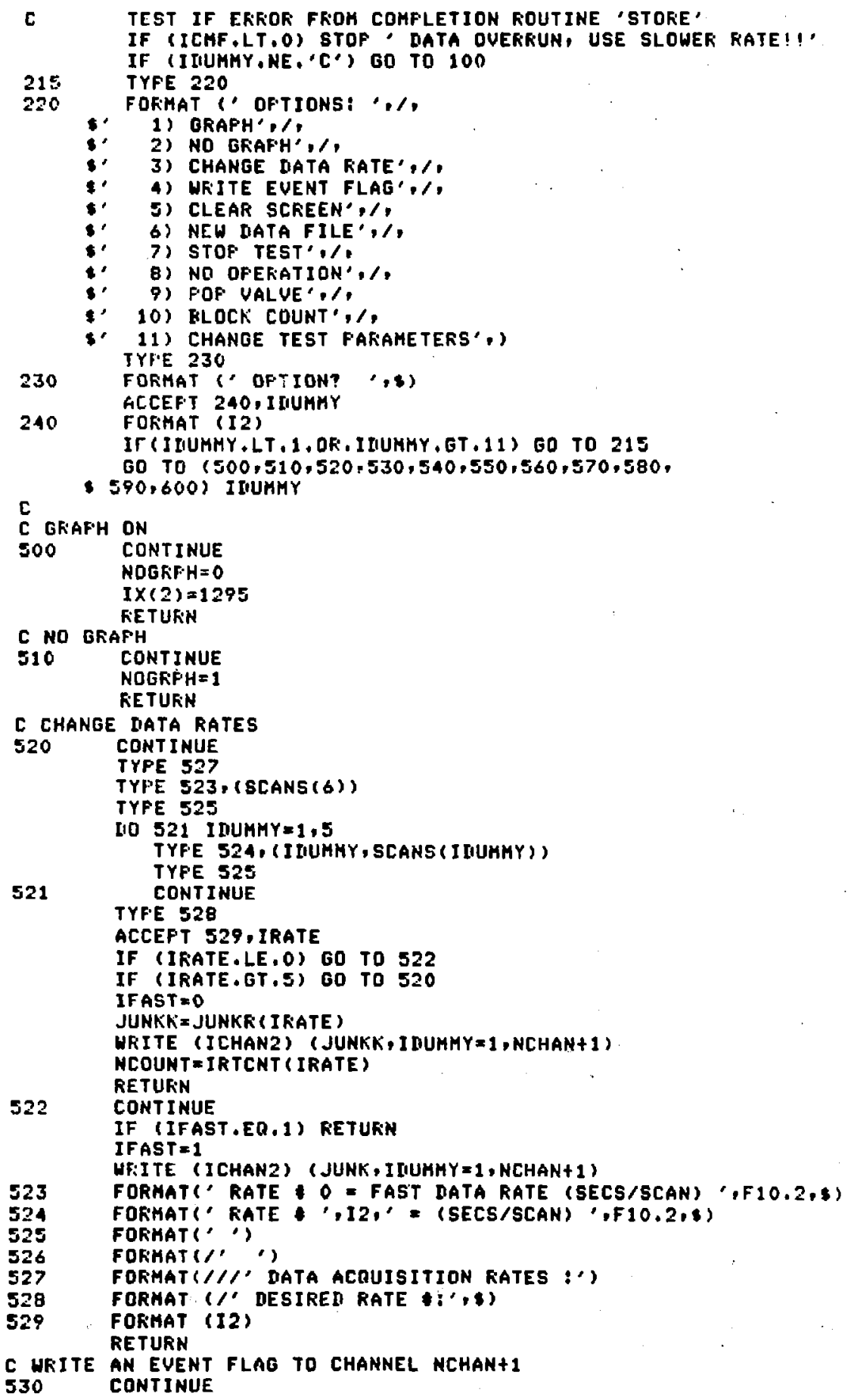


APPENDIX (cont)

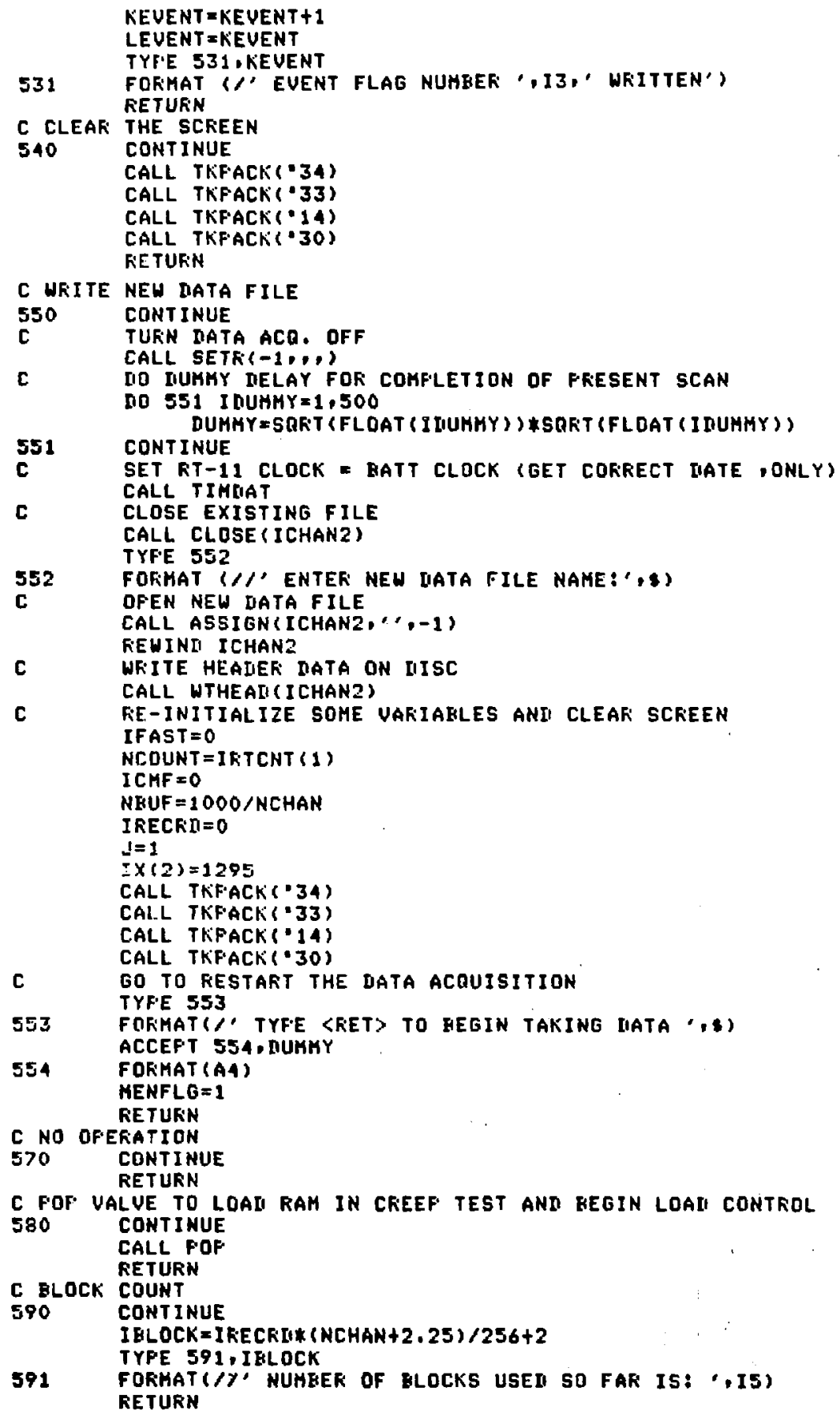




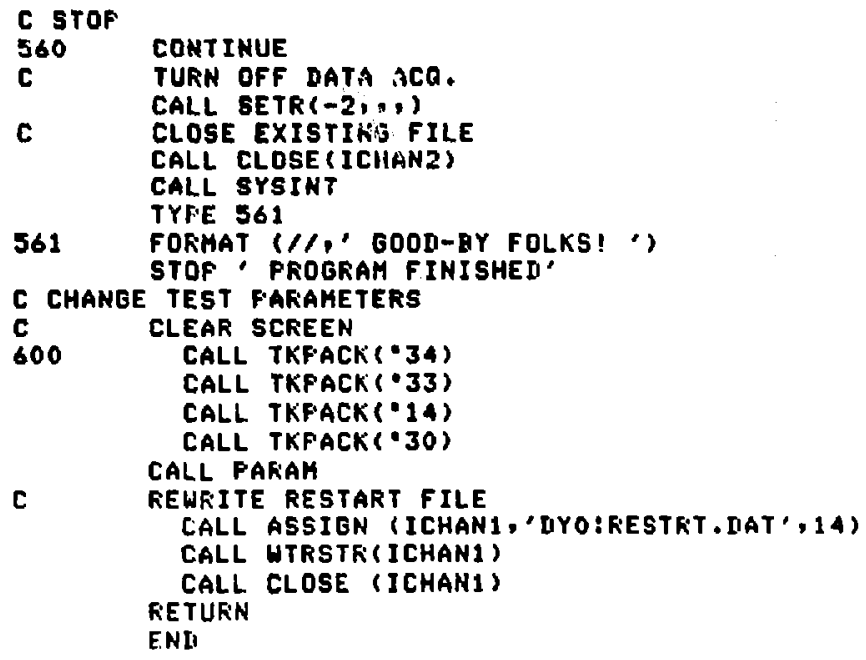

C CALCULATE. NEW AREA IN INCHES AREAHW $=$ (CI FNEW*CIRNEW $) /(4,0 * P I)$ RETURN END 


\section{APPENDIX (cont)}

SURKOUTINE PARAK

C PARAM COLLECTS ALL TEST PARAHETERS

CQMHON/CHANH/KLOAD, KCONF, KPORE, KDIFF, KRAI1, KKA[12, KKAL13

COMKON/TEST/ACPSI, AREANH, AXLCON, CIRREF, CONDSR , CFERNT , DIF ISF,

- GAUAXL, GAURAD, I CONFP, ICIRI, ICIRF, I CONF I, I CONFF, I IIFF I.

- ICFLAG , IFLAG , LOAIF, LOADI, I PORE, I POREF, FERCNT , PI , PISARE,

- RADCON, RLOAI, RSFLAG, SFDIA, SPIIAR,

C

- SNAXIL, SNCONF, SNIIFF, SNLOAI, SNPORE, SNKAIIL, STRSS1

1 TYPE 80

BB FOKHAT( $/ /$ ')

TYFE 200,SFDIA

CALL SAME (SFIIA)

TYFE 205, DIFDSR:

CALL SAME (IIFISR)

VAR $=100, * F E$ *ENT

TYPE 208, VAF

CALL SAKE (VAR)

FERECNT $\approx$ VAF/ 100

TYFE 210, CONISR

CALL SAME (CONDSF)

UAF: $=100$, $*$ CFERNT

TYFE 212, VAK

CALL SAME (UAR)

CFEKNT = UAK/100.

TYFE 225.SHLQAII

[Al. I. SAHE (SNLOAII)

TYFE 230, SNCONF

CALL SAME (SNCONF)

TYFE 235, SNFOKE

L.FLL SAME (SNFOKE)

TYFE 233, SNDIFF

CALL SAME (SNIIFF)

TYFE 240, GAUAXL

CGII.L SAME (GAUAXL)

TYFE 245, GAUKAI

[FLL. SAME (GAURAI!)

TYFE 250, SNAXIL

CALL SAME (SNAXIL)

TYFE 25S, SNKADL

CAL: SAME (SNEAIL)

C CALC, AXIFIL CONUERSION FACTOR

AXLCON=GAUAXL \$SNAXIL $/ 4096$.

C CALC, RAIIAL CONUERSION FACTOR

C FAIICON = GAURAL\#SNRAIUL/4096.

C FRINT DUT TEST PARAMETEKS

80 TYFE 89

Q9 FORMAT $(/ / 1,1)$

TYFE 200, SPDIA

TYFE 500

TYPE 205,DIFDSR

TYFE 500

VAR $=100$, HFERCNT

TYFE 20B.VAR

TYFE 500

TYF'E 210, CONDSR

TYFE 500

VAK : CFEKNT $\$ 100$.

TYFE 212, VAR

TYFE 500

TYPE 225,SNLOAD

TYFE 500

TYPE 230,SNCONF 


\section{APPENDIX (cont)}

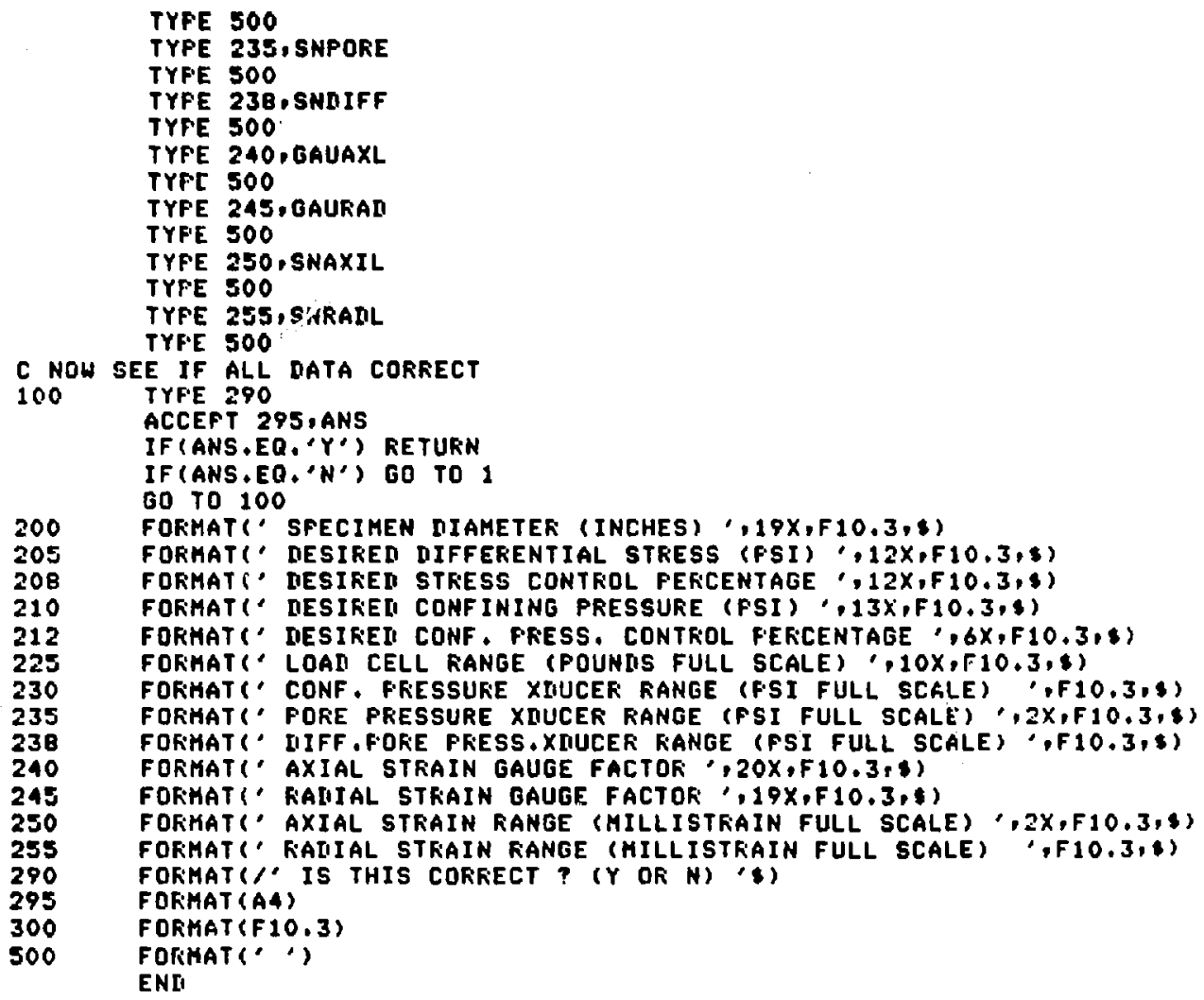




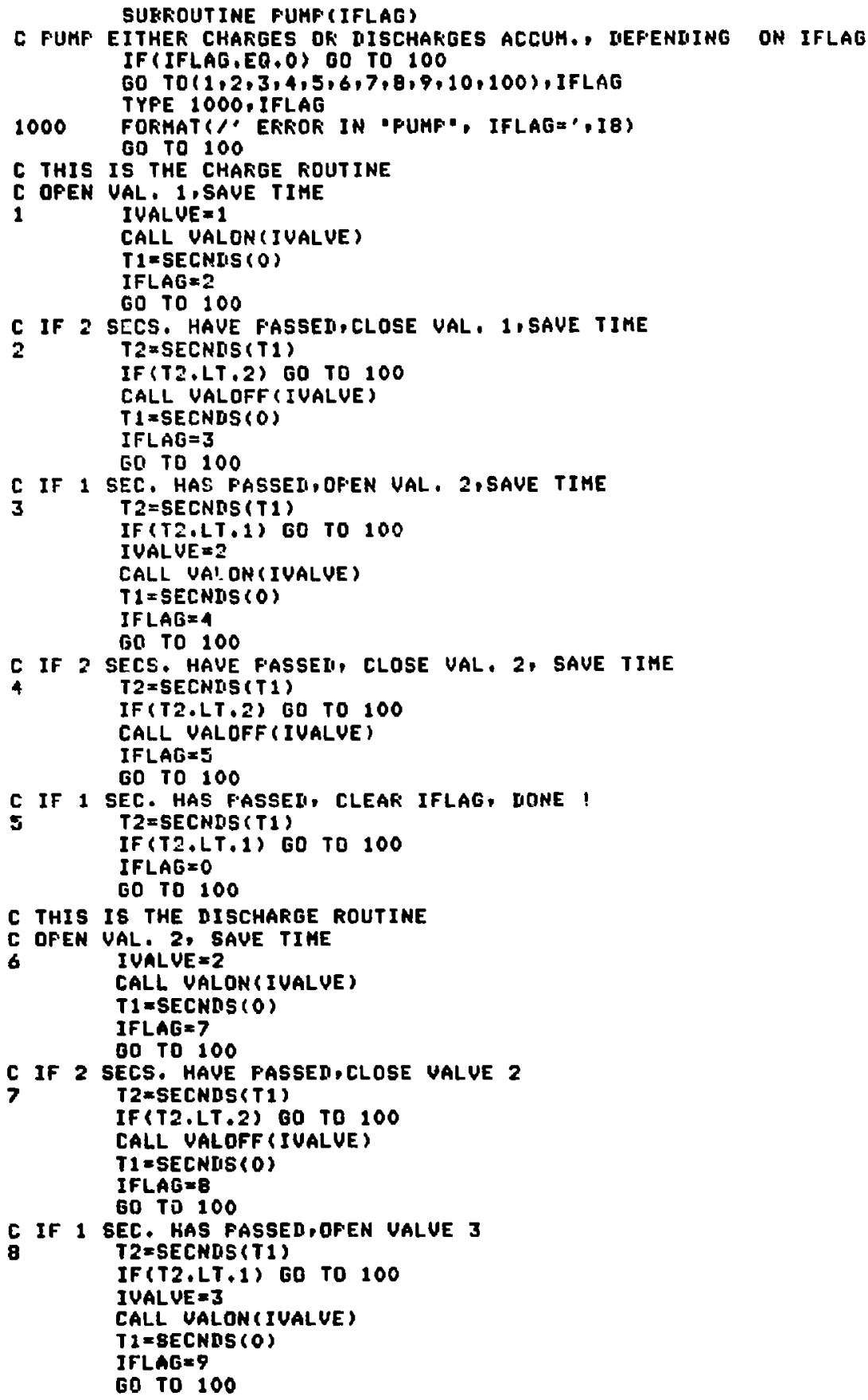




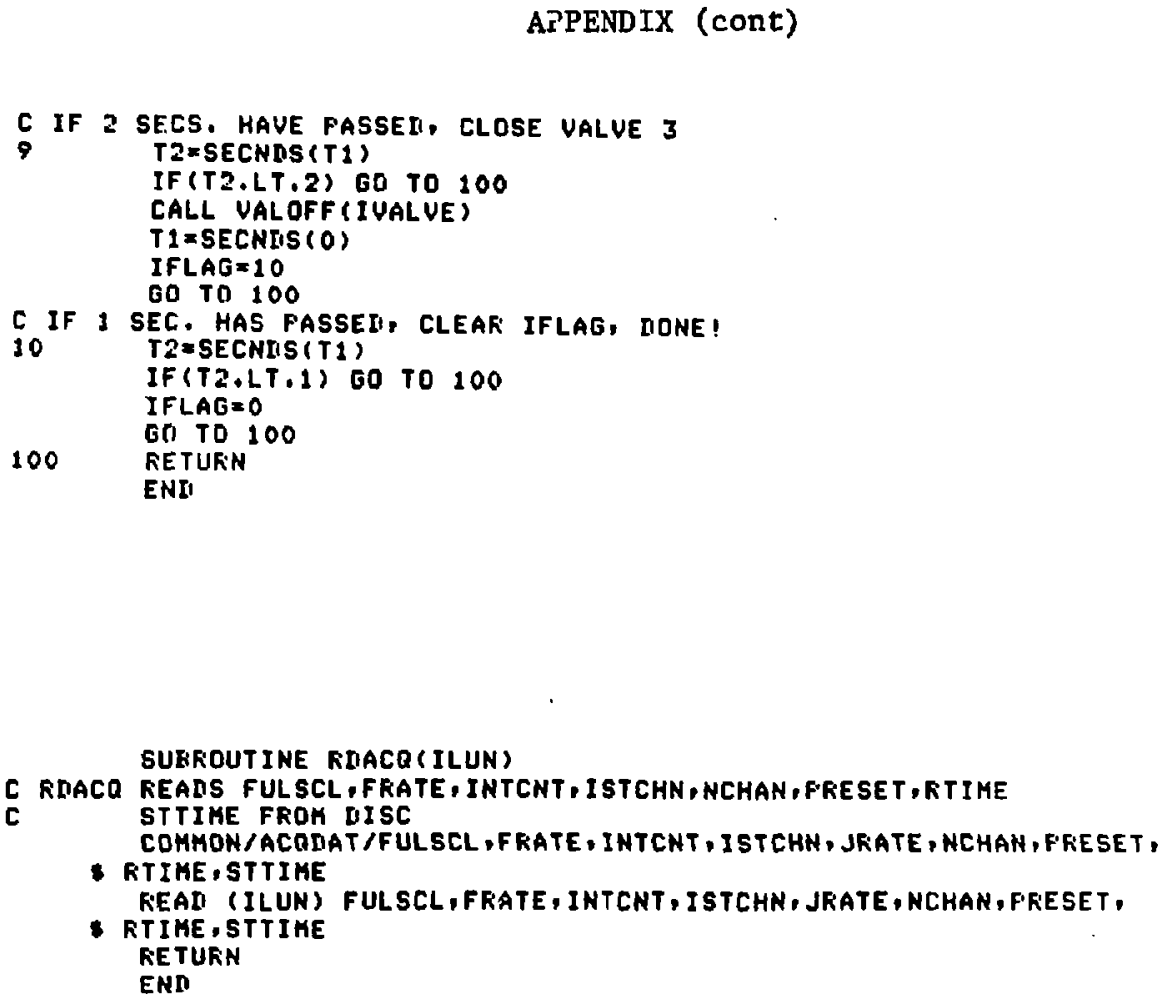




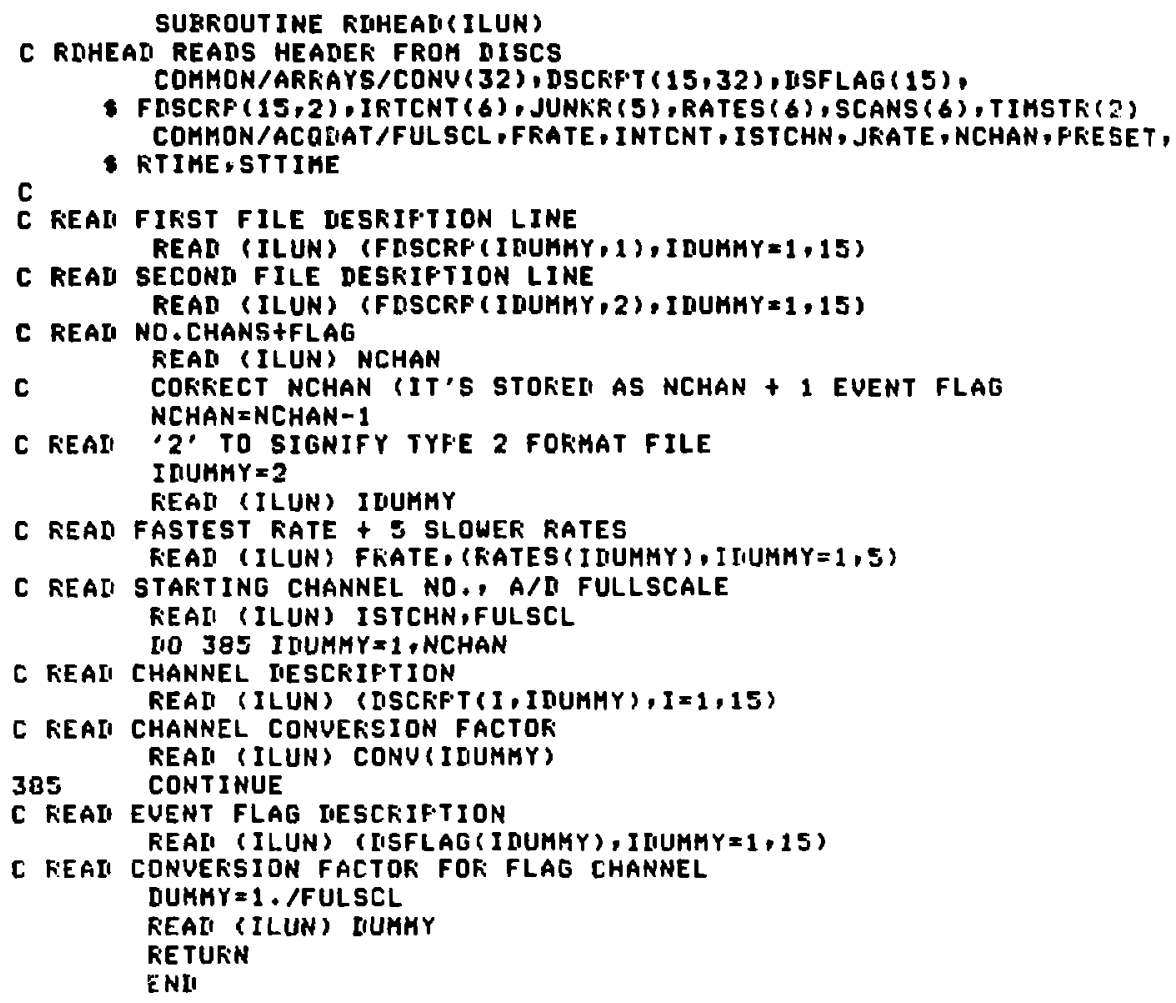


SUEROUTINE RITFAR(ILUN)

C RDTFAK READS TEST FARAKETERS FROM DISC COMMON/CHANN/KLOAD, KCONF , KFORE, KUIFF, KRAL1, KRAL2, KRALI3 COKMON/TEST/ACPSI, AREANW, AXLCON, CIRREF, CONOSR, CFERNT, DIF ISF,

- GAUAXL, GAURAL, I CONFF, ICIRI , I CIRF, ICONF I, I CONFF, I IIFF I,

- ICFLAG, IFLAG, LOADF , LOADI, IFORE, IPOREF, PERCNT, P I IPISARE,

- RAIICON, FLLOAL, RSFLAG, SFIIIA, SFIIAR',

- SNAXIL, SNCONF, SNIIFF, SNLOAD, SNPORE, SNKADL , STRSS1

C

REAII (ILUN) ACFSI, AKEANH, AXLCON, CIRREF, CONDSR, CPERNT, IIIFISK, - GAUAXL, OAURAD, ICONFF, ICIRI, ICIRF, ICONF I, ICONF , IDIFFI,

- ICFLAG , IFLAG , L OAIIF , LDAII I I IFORE , IFOREF , FERCNT , FI , FI SAKE ,

- RADCON, RLOAI, RSFLAG , SFIIIA, SFDIAR,

- SNAXIL, SNCONF, SNIIFF, SNLOAI, SNF'DKE, SNRAIL, STKSSI FEAII (ILUN) KLOAI, KCONF, KPORE, KDIFF, KRADI, KRALI, KRADZ RE TURN

E.NI

C NUN

SUEROUTINE FUN

CDNTKOLS IIFFERENTIAL STRESS ANI CONFINING FRESS. COMHON/CHANH/KLOAD, KCONF , KFORE, KDIFF , KRADI , KRAII , KRAII COMMON/FDFFLG/IFOF COMMON/FROCES/I BUF (1000), NEUF, I SIZ, NCOUNT,

- IFAST, ICHAN 1, ICHAN2, J,NOGRPH, IYO $(32), I X(2), L E U E N T$, IKECKI COMMON/TEST / ACF'S I AREANH, AXLCON, CIRFEF, CDNIISR, CFERNT, IIIF IISK,

- GAUAXL, GAURAD, ICONFF, ICIRI, ICIRF, ICONF I I CONFF, IDIFF I,

- ICFLAG, IFLAG , LOALF, LOADI IFOKE, IFOKEF, FERCNT , FI , FISARE,

- RAICON, RLOAI, RSFLAG , SFUIa, SFIIIAR,

- SNAXIL, SNCONF, SNIIFF, SNLOAI, SNFORE, SNRALIL , STRSS1

C

IIATA IFOF/OI

DATA ICFLAG/O/

C

IIATA IFLAL/O/

C IS UALUE. FOPFEU YET?

IF (IFOP .EQ.O) RETUKN

IVALVE $=0$

CALL VALOFF (IVALVE)

20 CONTINUE

C IF ICFLAG SET, FROCESS CONFHF, OTHERWISE TEST CONF, FRESS. IF (ICFLAG.GT.0) BO TO 1105

C IS CONFINING FRESSURE CORKECT ? 1 CONFF = I GUF ( ( J-ISTCHN $)+K C O N F)$ CONFFS = 5 NCONF * (ICONFF-ICONF I ) $/ 2048$. IF (CONPRS, GT , (CON[ISR $*(1$, +CFERNT) ) ) TCFLAG 1 IF (CONFFS . LT , (CONDSR* $(1,-C F \cdot E R N T))$ ) ICFLAG $=3$

1105 CALL CONFHF(ICFLAG)

C IF IFLAG SET, FROCESS PUHF, DTHERWISE TEST AXIAL STRESS IF (IFLAG.OT.O) GO TO 1150

C CALC. NEU SFECIHEN AREA CALL NWAFEA

C CALC, FRESENT IIIFFERENTIAL STRESS CALL AXSTRS

C IS IIFFERENTIAL STRESS = IESIRED ? IF (STRSS1.GT . (DIF DSR $\$(1$. +PERCNT)) ) IFLAG = IF(ETRSS1 - LT.(DIFDSR*(3.-PERCNT) )) IFLAÉ=1 CALL PUMF (IFLAG) RETURN ENII 
SUEFOUTINE SAMASC (VAR)

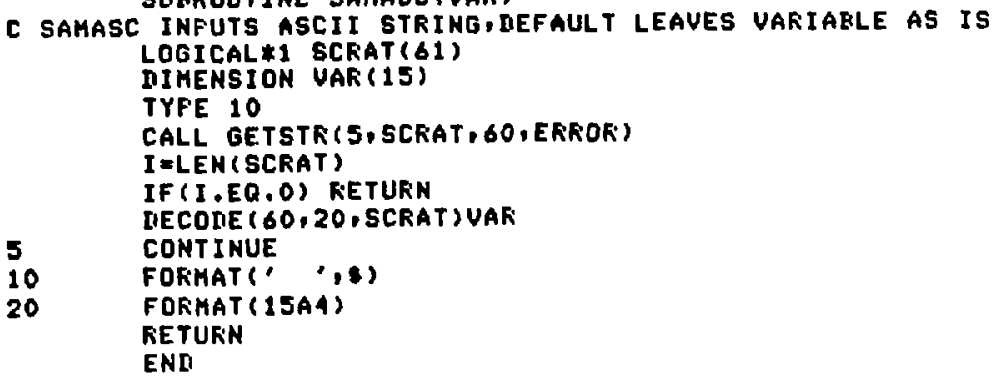

\section{BURROUTINE STORE}

C STOKE IS THE COMFLETION ROUTINE FOR DAT ACQ.

C THIS COMFLETION ROUTINE DOES THE FOLLOUING THINGS:

C 1: URITES THE DATA TO

C THE DISK FILE

C 2: GRAPHS EACH CHANMEL AS A FUNCTION OF TIHE ON THE

C ADM TERHINAL USING THE TK ORAPHICS SOFTHARE.

C 3: SLOH MOLE WDRKS AS FOLLOWS:

C A: HODE IS ACTIUE WHEN IFAST DOES NOT $=1$.

C D: DNCE EUERY NCOUNT CALLS TO THE GTDFE ROUTINE

C ONE SET OF DATA IS SAVED AND BTORED ON DISK

C AND FLOTTED ON THE AUM TERHIMAL.

C A\& FAST HOLE HORKS AS FOLLOUS:

C A: ACTIUATED EY IFAST $=1$.

C B: DATA FROH EVERY CALL TO THE gTORE ROUTINE IS

C STOREY DN DISK. 


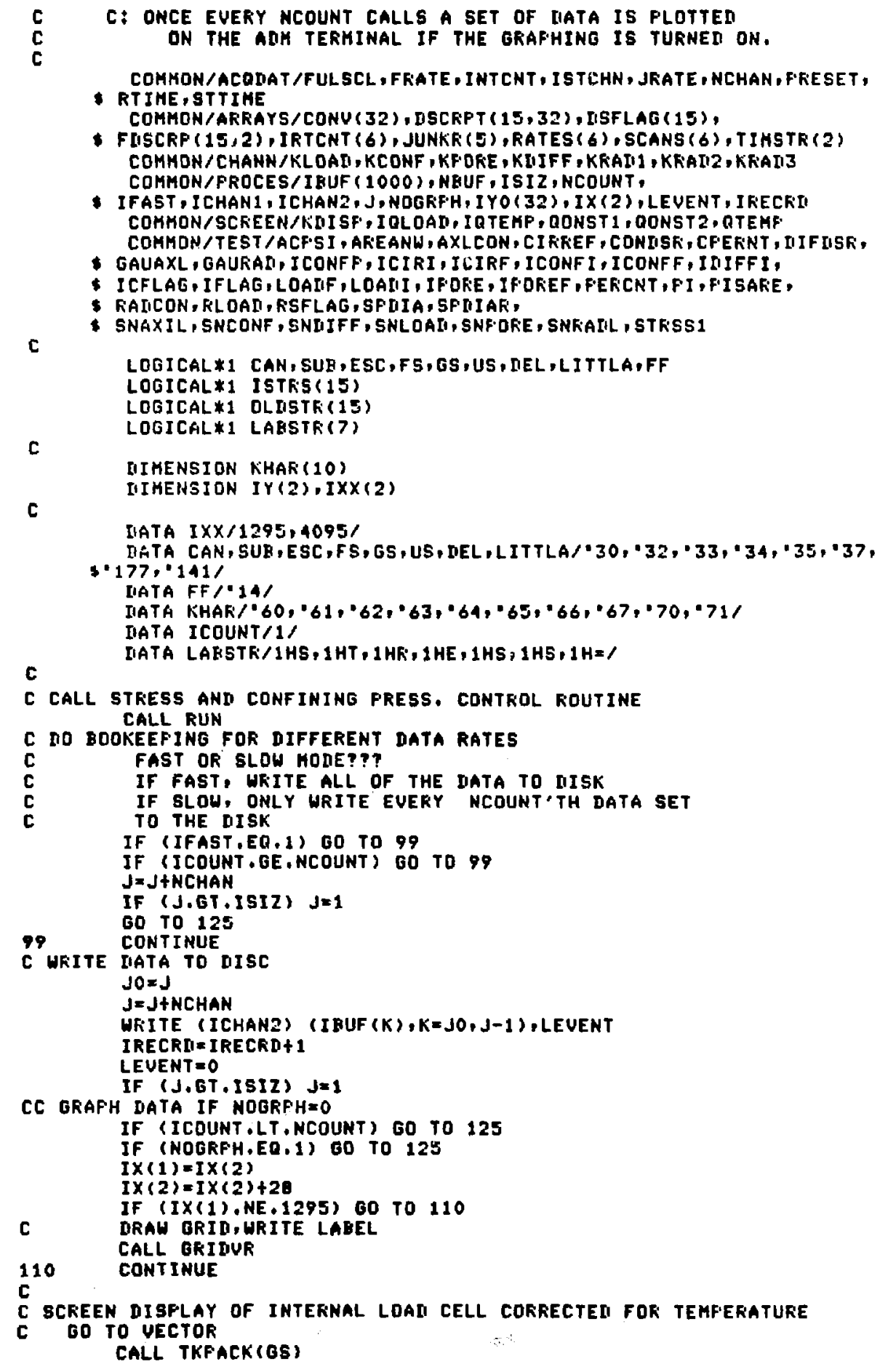




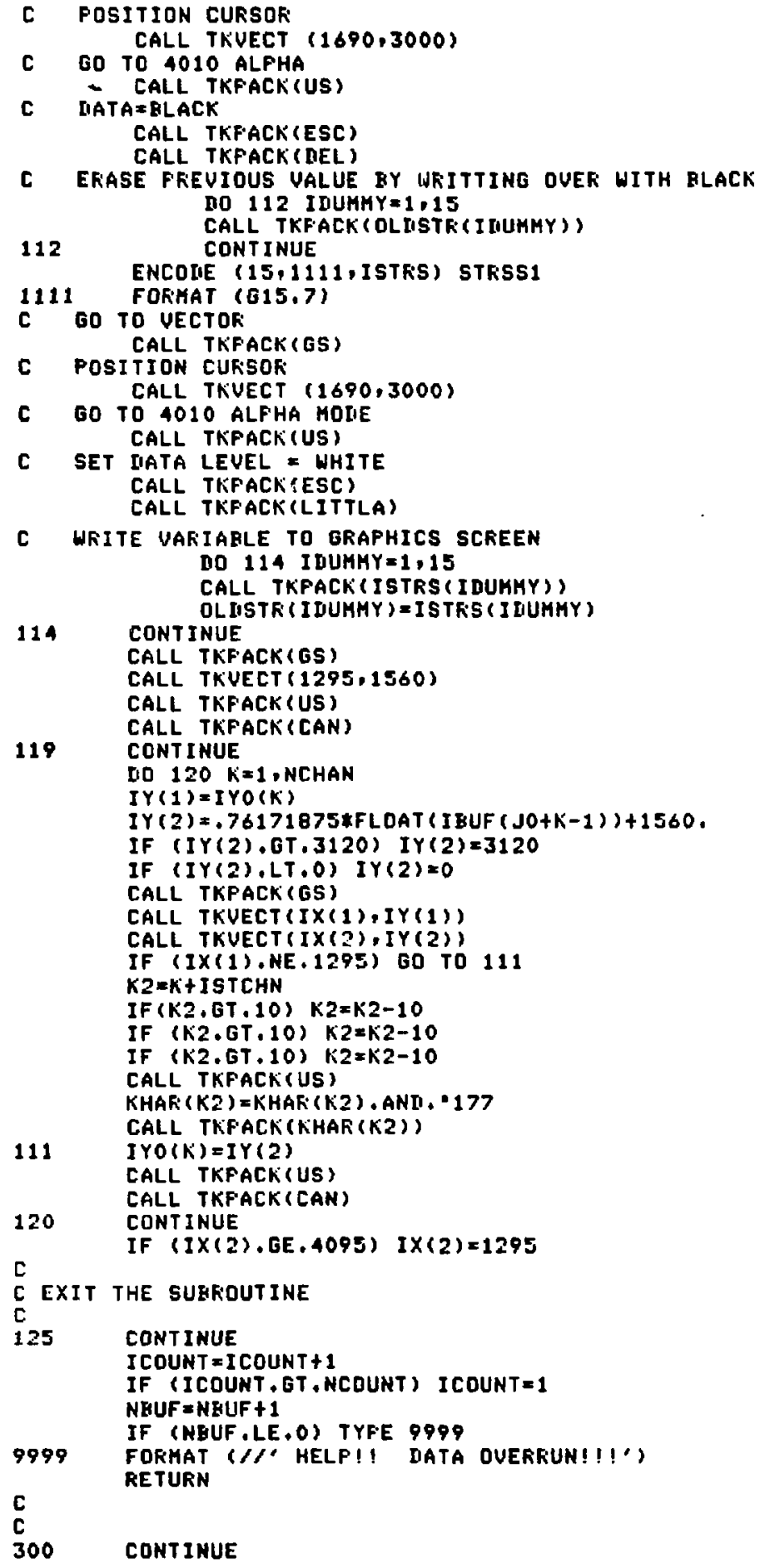




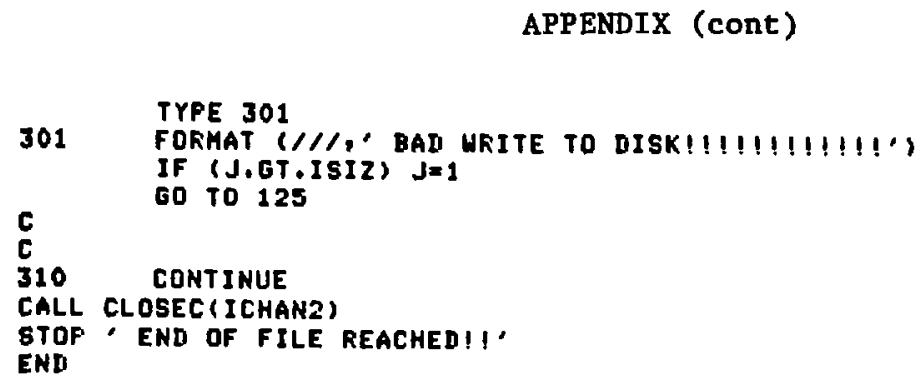


SUBFDUT INE WTARAY (ILUN)

C UTARAY WRITES ARRAYS CONU, IRTCNT, RATES, SCANS,TIMSTR TO DISC COMHON/ARRAYS/CONU (32), DSCRPT $(15,32)$, DSFLAG (15),

C

- FISCRF' (15,2), IRTCNT (6), JUNKR (5), RATES(6), SCANS (6), TIMSTR(2)

C URITE CONU

C WRITE IRTCNT WRITE (ILUN) (CONU (IIUMMY), IIUUMMY $=1,6$ )

C WRITE RATES WRITE (ILUN) (IKTCNT (I IUNHY), I IIUMMY =1,6)

c URITE SCANS WFITE (ILUN) (SCANS (IDUMMY), IDUMHY=1,6)

C WRITE TIHSTK WRITE (ILUN) TIHSTK RETURN END

SUEROUTINE WTHEAII(ILUN)

C WTHEAD WRITES HEADER TO DISC COHMON/AKFAYS/CONU (32), DSCRFT $(15,32)$, DSFLAG (15),

- FDSCRP (1S, 2), IRTCNT (6), JUNKR (5), RATES (6), SCANS (6), TIMSTR (2) COHMDN/ACQIAT/FULSCL, FRATE, INTCNT, I STCHN, JRATE , NCHAN, FRESET,

c - RTIHE,STTIHE

C WRITE FIRST FILE DESKIFTION LINE WRITE (ILUN) (FDSCRF (IDUMHY,1), IDUMMY=1,15)

C WRITE GECOND FILE DESRIFTION LINE HRITE (ILUN) (FDSCRP (IDUMHY, 2), I DUMHY = 1, 25)

c WRITE MO. CHANS+FLAG

C STOKE MCHAN $=$ NO.CHANMELS + 1 EVENT FLAG NCHAN=NCHAN+1

WRITE (ILUN) NCHAN

C CORRECT NCHAN MCHAN=NCHAN-1

C WRITE ' 2 ' TO SIGNIFY TYPE 2 FORHAT FILE IDUHMY $=2$ WFITE (ILUN) IUUMKY

C WRITE FASTEST RATE + 5 SLOUER RATES WRITE (ILUN) FRATE, (RATES (IDUKKY), I DUAMY $=1,5$ )

C MRITE STARTING CHANNEL NO., A/D FULLSCALE WRITE (ILUN) ISTCHN,FULSCL DO 385 I DUMMY 1 , NCHAN

C WRITE CHANNEL DESCRIFTION WRITE (ILUN) (ISCRPT(I, I DUHHY), I=1,15)

C WRITE CHANNEL CONUERSION FACTOR

385 CONTINUE

C HRITE EUENT FLAG DESCRIFTION WRITE (ILUN) (DSFLAG (IDUMMY), I DUHAY $=1,15$ )

C WRITE CONUEKSION FACTOR FOR FLAG CHANNEL IUUHKY $=1$. /FULSCL WRITE (ILUN) DUMMY RETURN ENI 


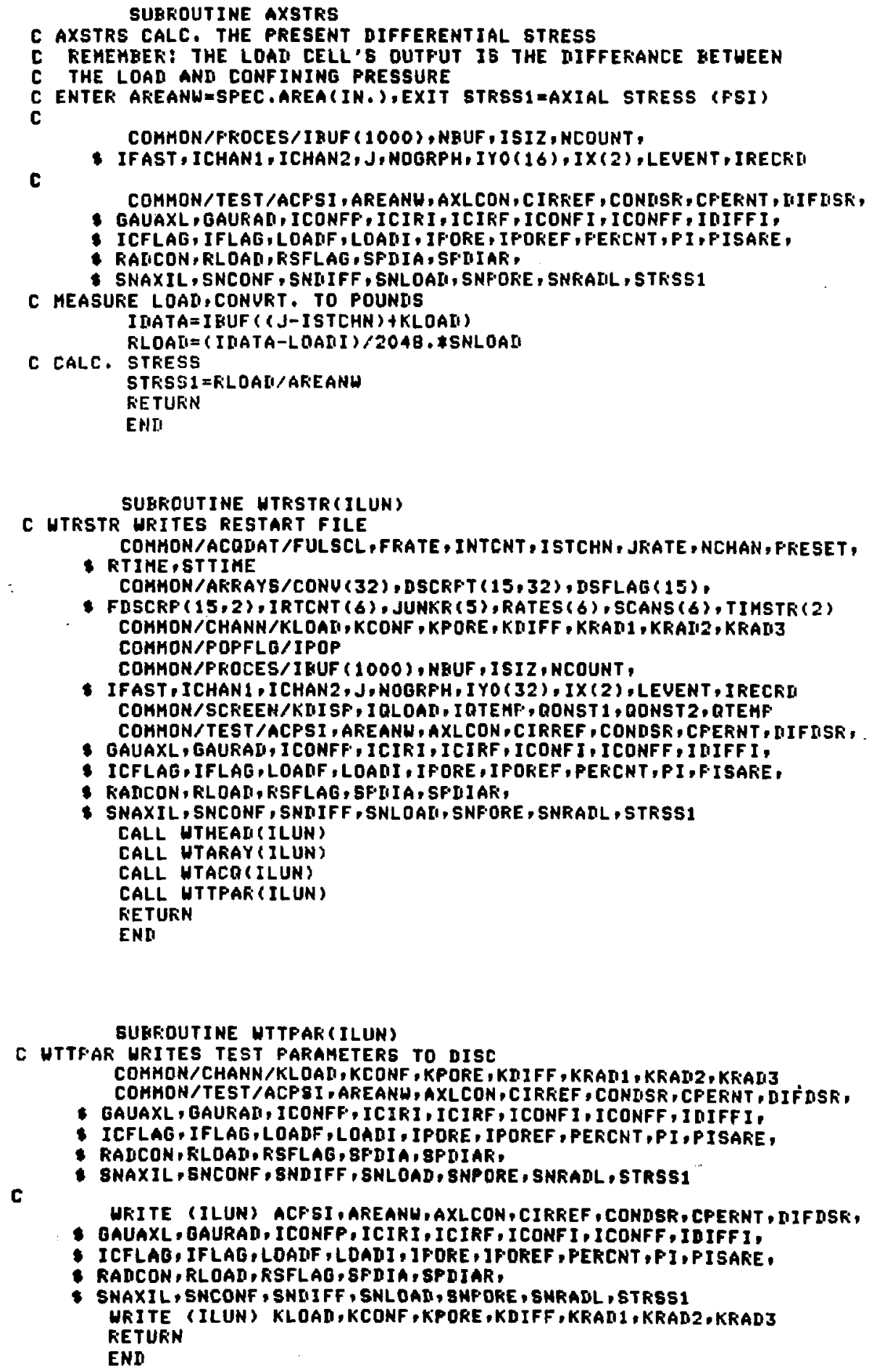

